\title{
HACIA LA CREACIÓN DE UNA «CONCIENCIA COLECTIVA» SOBRE LA HIGIENE Y SEGURIDAD LABORALES: LA MEDICINA DEL TRABAJO EN LA ACCIÓN EDUCATIVA SOBRE LOS PRODUCTORES (ESPAÑA, 1940-1980)*
}

\author{
Towards the creation of a "collective conscience" on hygiene and \\ safety at the workplace: occupational medicine and educational \\ action on workers (Spain, 1940-1980)
}

\section{José Martínez-Pérez ${ }^{\alpha}$}

Fecha de recepción: 15/04/2021 • Fecha de aceptación: 03/09/2021

Resumen. El régimen franquista expresó desde el primer momento su preocupación por los riesgos laborales. Accidentes del trabajo y enfermedades profesionales representaban, además de un problema de tipo humanitario, una amenaza para la producción. La Medicina del Trabajo representó así una disciplina relevante para contribuir a combatir los daños que causaba una inadecuada higiene y seguridad en el trabajo.

En este artículo se estudia el modo en que desde la Medicina del Trabajo se planteó el papel que, con el fin de reducir las tasas de siniestralidad y enfermedades laborales, podía desempeñar la educación de los obreros en el lugar de trabajo en materias relacionadas con la prevención de los riesgos derivados de la actividad productiva. Tomando como referencia la forma en que los expertos se manifestaron al respecto en sus publicaciones científicas, y las fuentes legislativas en que se expresaron sus planteamientos, se pone de relieve la forma en que las aportaciones que hicieron los especialistas españoles se ubicaban en línea con el objetivo del régimen de generar en los trabajadores una "conciencia colectiva» acerca de la necesidad de combatir la siniestralidad en el trabajo y las

\footnotetext{
* Este trabajo ha sido realizado en el marco del proyecto de investigación HAR2015-64150-C2-2-P (Ministerio de Economía y Competitividad).

${ }^{\alpha}$ Dpto. de Ciencias Médicas (Área: Historia de la Ciencia). Facultad de Medicina de Albacete, Universidad de Castilla-La Mancha. Avenida de Almansa, 14, 02006 Albacete, España. jose.mperez@uclm. es (D) http://orcid.org/0000-0001-8042-6244
}

Cómo citar este artículo: Martínez-Pérez, José. «Hacia la creación de una "conciencia colectiva" sobre la higiene y seguridad laborales: la medicina del trabajo en la acción educativa sobre los productores (España, 1940-1980)». Historia y Memoria de la Educación 15 (2022): 259-295 
enfermedades profesionales. Se pone de manifiesto también cómo esa labor de adoctrinamiento contribuyó a desarrollar el argumento de que cabía una responsabilidad por parte del trabajador en la pérdida de su salud.

Palabras clave: Historia de la Medicina del Trabajo; Seguridad e higiene del trabajo durante el franquismo; Medicina y educación de los trabajadores.

Abstract. The Franco regime expressed its concern about occupational hazards very early on. Accidents at work and occupational diseases were not only a humanitarian problem, but also a threat to production. Occupational medicine was thus seen as a discipline that could make an important contribution to combating the damage caused by inadequate hygiene and a lack of safety in the workplace.

This article examines how occupational medicine approached the role of educating workers about the prevention of occupational hazards in the workplace. Taking as a reference the ideas on this issue expressed by Spanish occupational medicine specialists in their scientific publications, and the legislative sources in which their approaches were incorporated, the article highlights how their contributions were in line with the regime's objective of generating, among workers, a "collective conscience" of the need to combat accidents at the workplace and occupational diseases. It also shows how this indoctrination helped to develop the argument that there was a responsibility on the part of the worker for the loss of his or her health.

Keywords: History of Occupational Medicine; Occupational safety and hygiene in Franco regime; Medicine and education of workers.

\section{INTRODUCCIÓN}

El nuevo orden político establecido en España tras la Guerra Civil dio tempranas muestras de preocupación por regular las cuestiones relativas al ámbito laboral. El Fuero del Trabajo, promulgado con anterioridad al fin de la contienda, ${ }^{1}$ mostraba los principios ideológicos en que se iba a desenvolver la Dictadura en relación con esa parcela de la actividad social. ${ }^{2}$ La norma ponía de manifiesto en su preámbulo la relevancia que se otorgaba al trabajo en cuanto agente capaz de contribuir a esa "producción

\footnotetext{
1 «Queda aprobado el Fuero del Trabajo formulado por el Consejo Nacional de Falange Española Tradicionalista y de la J.O.N.S., sobre una ponencia del Gobierno", Boletín Oficial del Estado (BOE, en adelante) 505 (10-marzo-1938): 6178-6181.

2 El Fuero del Trabajo representó una expresión del nacionalsindicalismo, que, en la manera en que lo formuló Falange Española, se convirtió en la fuente fundamental de los principios del sistema franquista. Sheelagh Ellwood, Historia de Falange Española (Barcelona: Crítica, 2001), p. XXX.
} 
española» que debía de servir a la «fortaleza de la Patria» y al sostenimiento de «los elementos de su poder». A través del Fuero, el nuevo régimen declaraba hallarse comprometido con: el ejercicio de «una acción constante y eficaz en defensa del trabajador, su vida y su trabajo» (Declaración 2.1); la labor de velar "por la seguridad y continuidad en el trabajo» (Declaración 3.6); y con proporcionar al productor la seguridad de sentirse protegido en caso de infortunio (Declaración X.1). De esta forma, las tareas que, como las que entraban en el ámbito de competencias de la Medicina del Trabajo, se relacionaban con la consecución de estos fines se ubicaban en una posición idónea para ser impulsadas por el gobierno franquista. ${ }^{3}$

Para llevar a cabo su labor en relación con los problemas relacionados con los riesgos laborales, la Dictadura aprovechó inicialmente una parte de las estructuras administrativas y legislativas de la etapa republicana. ${ }^{4}$ La decisión de mantener el Instituto Nacional de Previsión (INP, en adelante) puede interpretarse como una prueba de ello. Esta entidad, creada en 1908 para la administración de un seguro de pensiones y la promoción de la previsión social, fue encargada en 1933 por el Gobierno de la República de gestionar un nuevo organismo: la Caja Nacional de Seguro contra Accidentes del Trabajo. ${ }^{5}$ Para poder cumplir con sus cometidos, ${ }^{6}$ se creó la Clínica del Trabajo, ${ }^{7}$ que se ha considerado crucial

\footnotetext{
${ }_{3}^{3}$ Sobre esta relevancia otorgada por el régimen al trabajo, y sus consecuencias sobre la Medicina, ver: José Martínez-Pérez y Mercedes Del Cura, «Bolstering the greatness of the Homeland: Productivity, Disability and Medicine in Franco's Spain (1940-1966)», Social History of Medicine 28 (4), (2015): 805-824. Doi: 10.1093/shm/hkv060.

4 Alfredo Montoya Melgar, Ideología y las Leyes Laborales de España (1873-1978) (Madrid: Civitas, 1992), 338 y 349.

${ }^{5}$ Fue creada en respuesta al mandato contenido (Art. 45) en el Decreto por el que se promulgó la Ley de accidentes del trabajo de 1932. «Decreto de 8 de octubre de 1932 por el que se promulga el texto refundido de la legislación de Accidentes del trabajo en la industria», Gaceta de Madrid 286 (12-octubre-1932): 218-224. Trataba de responder a los cambios en el modo de interpretar y abordar la siniestralidad laboral, concretados en la sustitución del sistema de indemnización por el de renta, y en el principio de seguro obligatorio de accidentes. Luis Jordana de Pozas, La Caja Nacional de Accidentes del trabajo y sus primeros resultados (Madrid: Instituto Nacional de Previsión, 1933), 3 y 7.
}

${ }^{6}$ Sus Estatutos establecieron que, entre otras cosas, debía de encargase de: los servicios médicos de inspección y revisión de incapacidades permanentes; del servicio de readaptación funcional de las personas accidentadas; y del estudio, difusión y publicidad de todo lo que pudiera contribuir a la disminución del riesgo de los accidentes laborales. «Decreto de 22 de febrero de 1933 por el que se aprueban los Estatutos de la Caja Nacional de Seguros de Accidentes del Trabajo», BOE 56 (25-febrero-1933): 1531-1535 (p. 1532).

7 La Clínica del Trabajo del Instituto Nacional de Previsión (Madrid: Publicaciones del Instituto Nacional de Previsión-Unión Poligráfica, 1934). 
dentro del desarrollo de la Medicina del Trabajo en España. ${ }^{8}$ Dado que el régimen franquista restableció el INP — tras ajustarlo a las consignas y orientaciones del Nuevo Estado-, ${ }^{9}$ la Clínica del Trabajo continuó desplegando su actividad durante el Franquismo. ${ }^{10}$

Es importante destacar para los objetivos de este artículo que, desde muy pronto, el régimen franquista no solo dio muestras de preocupación por las consecuencias negativas de la siniestralidad laboral para el devenir del Estado, sino que también iba a establecer la posibilidad de considerar a las víctimas de los accidentes responsables de ellos. El Reglamento de Seguridad e Higiene de 31 de enero de 1940, cuyo objetivo era reducir el número y gravedad de los accidentes «mediante una intensa labor preventiva» en la que habrían de intervenir «todos cuantos tienen relación con este problema»,11 estableció en su artículo tercero que los trabajadores que incumplieran «cualquier precepto legal sobre seguridad e higiene del trabajo» podían recibir sanciones.

La Medicina del Trabajo encontró así un terreno abonado para desarrollarse a través de la ejecución de tareas que, como la prevención de la siniestralidad laboral, el peritaje forense de las lesiones, la intervención sobre los trabajadores accidentados para devolverlos a la actividad productiva o la de fortalecerlos para mejorar su rendimiento, contribuían a impedir una disminución de la mano de obra activa y a mejorar la producción. Es más, su relevancia para las autoridades franquistas iba también a venir por su capacidad para aportar algo que estas esperaban de los médicos: que ayudaran al sostenimiento del régimen franquista realizando labores de propaganda encaminadas a ganar nuevos adeptos. ${ }^{12}$

Se otorgaba así a la Medicina del Trabajo una posición destacada de cara a la consecución de importantes objetivos del régimen franquista,

\footnotetext{
8 Ángel Bachiller Baeza, La Medicina Social en España (El Instituto de Reeducación y la Clínica del Trabajo 1922-1937) (Valladolid: Universidad de Valladolid, 1985).

9 «Decreto de 15 de junio de 1938 sobre la nueva organización del Instituto Nacional de Previsión», BOE 610 (24-junio-1938): 7999-8001 (p. 7999).

10 «El Excmo. Sr. Ministro de Trabajo inaugura la Clínica del Trabajo». Caja Nacional de Seguro de Accidentes del Trabajo. Boletín de Información 6 (1940): 9-13.

11 «Orden de 31 de enero de 1940 aprobando el Reglamento general de Higiene y Seguridad en el Trabajo», BOE 34 (3-febrero-1940): 914-924 (p. 914).

12 José Antonio Girón, Medicina Social. SER 6 (1942): 7-8.
} 
lo que habría de conducir a que se apoyara su desarrollo. En 1943 el Ministerio del Trabajo convocó y organizó el Primer Congreso Nacional de Medicina y Seguridad en el Trabajo. Me interesa destacar ahora que entre las conclusiones de esa reunión figuraban las de fomentar la enseñanza de la higiene y seguridad en el trabajo y la de llevar a cabo una labor educativa entre los productores, algo que se consideraba «uno de los medios más eficaces de lucha» contra la siniestralidad laboral. ${ }^{13}$

Una consecuencia significativa de ello fue que la formación de los productores en relación con la seguridad e higiene del trabajo iba a ser considerada como un ingrediente importante del conjunto de medidas que el Nuevo Estado iba desplegar para reducir las tasas de accidentes laborales y las enfermedades profesionales. Aunque desde la Medicina del Trabajo se había venido defendido con anterioridad la necesidad de ejercer una acción educativa en ese sentido, ${ }^{14}$ como mostraré en este artículo, pues ello constituye su objetivo fundamental,,$^{15}$ ese ingrediente no iba a faltar en las sucesivas recetas que se formularon desde esa especialidad médica, y desde el régimen franquista, para gestionar el problema que los riesgos laborales planteaban. Y es que, como intentaré poner de manifiesto utilizando principalmente fuentes normativas y publicaciones de los expertos en higiene y seguridad en el trabajo, esa labor educativa iba a ser contemplada no solo como una herramienta útil para generar en los productores una «conciencia colectiva» acerca de la necesidad de combatir los riesgos para su salud, sino también para mejorar las posibilidades de conseguir dos metas importantes para quienes iban a gobernar España durante más de cuarenta años: elevar la producción, y facilitar el ejercicio del control social.

Para ponerlo de relieve, dividiré mi exposición en cuatro apartados. En el primero me ocuparé de las décadas de los cuarenta y cincuenta.

13 Congreso Nacional de Medicina y Seguridad en el Trabajo. Bilbao, agosto 1943 (Madrid: Ministerio de Trabajo, 1944), 392-393.

14 José Martínez-Pérez, «La Organización Científica del Trabajo y las estrategias médicas de seguridad laboral en España (1922-1936)», Dynamis 14 (1994): 131-158

${ }^{15}$ A lo largo de la etapa franquista los especialistas en Medicina del Trabajo mantuvieron, como habían hecho con anterioridad, la idea de que una adecuada formación profesional constituía una manera importante de reducir la siniestralidad laboral. Mi intención en esta aportación es, sin embargo, la de centrarme en la manera en que fomentaron la educación de los trabajadores en la seguridad y prevención de las enfermedades en el lugar de trabajo. 
Mostraré allí cómo se fue fraguando en esa etapa una estructura normativa e institucional que dio cobijo a esa labor formativa en materia de higiene y seguridad en el trabajo dirigida a los productores. A continuación, exploraré cómo, en la década de los sesenta, los cambios operados en el modo de concebir la Medicina del Trabajo facilitaron que la presencia de la educación de los trabajadores en materias relativas a prevenir los riesgos laborales cobrara un impulso notable. Posteriormente, me ocuparé de la manera en que, en los primeros años de la década de los setenta, se incrementaron las posibilidades de alcanzar esa ansiada "conciencia colectiva» acerca de la necesidad de evitar los accidentes del trabajo y de combatir las enfermedades profesionales, y plantearé algunas posibles consecuencias que estimo que se desprendían de ello. El último apartado lo dedicaré a poner de relieve cómo, en los años finales de la década de los setenta, continuó manteniéndose la idea de que era conveniente realizar una labor pedagógica sobre los trabajadores para realizar un mejor control de los riesgos laborales.

\section{LA CRECIENTE PREOCUPACIÓN POR LA HIGIENE Y SEGURIDAD EN EL TRABAJO}

A mediados de 1941, el Ministerio del Trabajo promovió entre las grandes empresas industriales una campaña para la creación de Comités de Seguridad e Higiene del Trabajo. Eso dio lugar a la instauración de cerca de trescientos de ellos, cuyos «satisfactorios resultados» aconsejaron generalizar su implantación con carácter obligatorio en 1944 dentro de aquellos establecimientos que contaran con un determinado número de trabajadores y lo exigiera la naturaleza del trabajo que se realizara en ellos. ${ }^{16}$ Además de la labor de vigilar el cumplimiento de la legislación relativa a la higiene y seguridad en el trabajo, ${ }^{17}$ figuraba también entre sus funciones la de organizar las labores de enseñanza,

\footnotetext{
16 "Orden sobre creación de Comités de Seguridad e Higiene del Trabajo», BOE 274 (30-septiembre1944): 7260-7261 (p. 7260).

${ }^{17}$ Las competencias de los Comités fueron asignadas en 1953 a los denominados Jurados de Empresa, que habían sido creados en 1945 ( Decreto de 18 de agosto de 1947 por el que se crean los Jurados de Empresa», BOE 282 (5-agosto-1947): 5568-5569, mediante la publicación de su Reglamento. «Decreto de 11 de septiembre de 1953 por el que se aprueba el Reglamento de los Jurados de Empresa», BOE 308 (30-octubre-1953): 6416-6422.
} 
divulgación y propaganda entre el personal. ${ }^{18}$ Se confiaba en que representaban una fórmula adecuada para conseguir «despertar el instinto de seguridad de todas y cada una de las personas» que integraban las empresas. ${ }^{19}$ En la Compañía Metropolitano de Madrid, por ejemplo, se habrían colocado «carteles aleccionadores sobre los riesgos en el trabajo y consejos para evitarlos en los lugares más estratégicos» de las empresas, y los integrantes del Comité de Empresa llevarían «permanentemente cerca de todos los agentes una acción de propaganda sobre los distintos problemas y medidas de seguridad e higiene en el trabajo».20

A esta tarea, ${ }^{21}$ que se puede interpretar como una de las vías mediante las cuales los comités llevaban a cabo esa misión que se les ha atribuido de ser un instrumento para mantener el orden, mejorar la productividad y extender los principios del nacionalsindicalismo, 22 iba a contribuir la

\footnotetext{
18 Perdiguero-Gil ha puesto de manifiesto cómo las actuaciones realizadas en los años veinte y treinta, dirigidas a transformar las conductas de la población para adecuarlas a las consignas de los expertos sanitarios, se ubicaron bajo la denominación de "propaganda». El influjo procedente del exterior hizo crecer el concepto de «educación sanitaria popular», aunque durante el período que considero en este trabajo "propaganda sanitaria» y «educación sanitaria» coexistieron. Enrique Perdiguero-Gil, "La "educación sanitaria" en el ideario médico-social del franquismo a través de la revista SER», en Política, salud y enfermedad en España: entre el desarrollismo y la transición democrática, ed. Enrique Perdiguero-Gil. (Alicante: Universidad Miguel Hernández de Elche, 2015), 117-135, https://editorial.edu.umh.es/2015/12/09/politica-salud-y-enfermedad-en-espana-entre-el-desarrollismo-y-la-transicion-democratica/.
}

19 Octavio Aparicio, «El Comité de Seguridad e Higiene de la "Standard Eléctrica" S. A.». Medicina y Seguridad del Trabajo. Revista del Instituto de Medicina y Seguridad del Trabajo 2 (5), (1953): 92-97 (p. 97). En adelante me referiré a esta revista con el acrónimo MST.

${ }^{20}$ Octavio Aparicio, «Los Servicios sanitarios y de seguridad de la Compañía Metropolitano de Madrid». MST (1955): 98-100, p. 100. Se ha desarrollado una cuantiosa e interesante labor historiográfica sobre el trabajo de los médicos destinado a llevar su conocimiento científico a la población. Ello ha servido para destacar su relevancia como factor modificador de las conductas, y su papel en relación con el crecimiento hegemónico de los médicos en relación con el manejo de los problemas de salud. Para una aproximación a esta bibliografía puede verse: José Martínez-Pérez y Mercedes Del Cura, «Divulgando nuevas ideas sobre la diversidad humana: la dimensión educativa del discurso sobre la discapacidad en la España franquista», Asclepio 71 (1), (2019). https://doi.org/10.3989/asclepio.2019.07.

${ }^{21}$ Sobre el uso político de la propaganda en la España franquista pueden verse: Marie-Aline Barrachina, Propagande et culture dans l'Espagne franquiste, 1936-1945 (Grenoble: ELLUG, 1998); y Carme Molinero, La captación de las masas. Política social y propaganda en el régimen franquista (Madrid: Cátedra, 2005).

22 Manuel Carlo Palomeque López, «La Ordenación Jurídica de la seguridad e higiene en el trabajo durante el primer y segundo franquismo, de la Guerra Civil a la Ordenanza General, 1939-1971», en Historia de la prevención de riesgos laborales en España, (s.e.) (Madrid: Fundación Francisco Largo Caballero-Fundación 1. ${ }^{\circ}$ de Mayo-Instituto Nacional de Seguridad e Higiene en el Trabajo, 2007), 122-139 (p. 131). Sobre estos Comités puede verse también: Julio A. Fernández Gómez, «De la 
actividad que se realizaría en el centro que operará como referente de la Medicina del Trabajo en España en las décadas siguientes: el Instituto Nacional de Medicina, Higiene y Seguridad del Trabajo (INMHST, en adelante). ${ }^{23}$ Creado en 1944, se buscaba que sirviera para mejorar la producción y las condiciones de vida de los trabajadores. Para ello, se le asignaban, entre otras funciones: investigar sobre las causas de la siniestralidad laboral; formar expertos en Medicina del Trabajo; y realizar labores destinadas a «inspirar una acción eficaz y una propaganda efectiva, especialmente en materia de prevención de accidentes del trabajo». ${ }^{24}$

La labor de educar a los productores en cuestiones relacionadas con la higiene y seguridad laborales iba pues adquiriendo un lugar cada vez más significativo entre los contenidos de la Medicina del Trabajo. Los expertos consideraban que «con su enseñanza realizaban una labor de carácter económico-social del más alto interés», y manifestaban su valor para:

Desarrollar en los obreros ciertos hábitos físicos, como equilibrio y sentido del movimiento y de la distancia; hábitos de orden intelectual, como son la atención, la prudencia, prevención, etc., y hábitos de índole moral, como paciencia, dominio de sí mismo, etc., única manera de eliminar la causa de los accidentes, cuya existencia nos ha puesto de manifiesto la moderna ciencia psicotécnica. ${ }^{25}$

La tarea formativa sobre los obreros en materia de seguridad laboral encontraba por tanto un argumento para su legitimación a través de las aportaciones que la Medicina del Trabajo venía realizando en la línea de considerar al «factor humano» como responsable de la mayor parte de los casos de la siniestralidad laboral. ${ }^{26}$ Se consideraba que entre el $80 \%$

Guerra Civil a la Ordenanza General de Seguridad e Higiene del Trabajo (1939-1971)», Sociología del Trabajo (nueva época) 6 (2007): 77-111 (pp. 91-93).

${ }^{23}$ Esta institución ha sido considerada como la impulsora de la moderna Medicina del Trabajo en España. Luis Fernández Conradi y Ángel Bartolomé Pineda, «Instituto Nacional de Medicina y Seguridad en el Trabajo», en Historia de la Medicina del Trabajo en España (1800-2000), eds. Ángel Bartolomé Pineda y cols. (Madrid: MAPFRE, 2004), 545-570 (p. 549).

${ }_{24}$ «Decreto de 7 de julio de 1944 por el que se crea el Instituto Nacional de Medicina, Higiene y Seguridad del Trabajo». BOE 208 (26-julio-1944): 5707-5709.

${ }_{25}$ M. Villar, «Necesidad de realizar la educación de la seguridad», MST 2 (9), (1954): 88-90 (p. 88).

${ }^{26}$ Cfr. José Martínez-Pérez y Mercedes Del Cura, «Work injuries, scientific management and the production of disabled bodies in Spain, 1920-1936», en The Imperfect Historian - Disabilities Histories in 
y el $85 \%$ de los accidentes no se deberían ni a la técnica, ni a carencias en los mecanismos de trabajo, sino a «defectos en el obrero». Era preciso por ello educarle a distintos niveles —físico, intelectual y moral—al objeto de inculcarle «las medidas de prudencia que debe tomar» para evitarlos. ${ }^{27}$ Se abogaba asimismo por actuar en ese sentido a través de una metodología que debería incluir: la expresión verbal —las conferencias podían ofrecer buenos resultados—; la escrita — publicación de folletos y revistas, cuya redacción debería ser clara y amena-; y la gráfica —que sería el procedimiento más eficaz-. ${ }^{28}$ De este modo, aunque los expertos no abandonaban la idea de que las deficientes condiciones de trabajo, o el uso de herramientas y equipos mal diseñados, representaban factores importantes en el origen de los accidentes, estaban contribuyendo a desplazar hacia los obreros un grado considerable de responsabilidad en el origen de la patología laboral. ${ }^{29}$ Las propias víctimas quedaban así rodeadas de un halo de sospecha acerca del grado de culpabilidad que les podía corresponder con respecto a la pérdida de su salud.

Por otra parte, debido a que se precisaba seleccionar médicos con título de especialista para atender el «incremento de accidentes y enfermedades profesionales» que el crecimiento industrial estaría provocando, se creó en 1948 la Escuela Nacional de Medicina del Trabajo, cuyas labores formativas en relación con la higiene y seguridad laborales se debían dirigir tanto a los médicos, como a los productores. ${ }^{30}$ Se alentó así la creación de un grupo de especialistas capaces de contribuir con su magisterio a adoctrinar a los trabajadores en la necesidad de protegerse de los riesgos laborales.

Europe, eds. Sebastian Barsch, Anne Klein y Pieter Verstraete (Frankfurt am Main: Peter Lang, 2013), 191-213.

27 Villar, «Necesidad de realizar», 88.

28 Villar, «Necesidad de realizar», 89.

${ }_{29}$ Un experto, que se planteaba la cuestión acerca de a quién debería ser atribuida la culpa de los accidentes del trabajo, respondía que «la tuvo tanto aquel empresario que en su empresa no realizó la oportuna propaganda preventiva y no tomó las medidas oportunas», como también «el obrero que no atendió aquellas recomendaciones que se le hicieron o no hace caso de las medidas que se dictan sobre el particular». E. Salinas de Salazar, «Una pregunta tardía en el quirófano ¿Quién tuvo la culpa?», MST 2 (7) (1954): 66-68.

30 «Decreto de 16 de enero de 1948 por el que se organiza la Escuela Nacional de Medicina del Trabajo», BOE 36 (5- febrero-1948): 532-533 (p. 532). 
En la década de los cincuenta se procedió a dar un impulso a esta línea de actuaciones dotando en 1952 de una nueva sede al INMHST y a la Escuela Nacional de Medicina del Trabajo. ${ }^{31}$ De acuerdo con la organización del Instituto se reservaba un espacio relevante al servicio de divulgación, al considerarse que «el factor de la propaganda o divulgación preventiva» entre empresarios y obreros poseía un carácter primordial para abordar los problemas médicos y de seguridad en el trabajo. ${ }^{32}$ Además, en sus programas formativos se incluían cuestiones como «la información general sobre las medidas higiénicas y de seguridad, ambiente científico, educación preventiva y educación sanitaria», que tendrían entre sus objetivos «estimular en el ambiente laboral el patriotismo, la labor social, la cultura, la colaboración de la Empresa, el bienestar propio y familiar, el mejoramiento económico, la educación profesional y el mejoramiento científico". ${ }^{33}$ Con ello se pretendía vencer «la apatía, la indisciplina, la incomprensión del capital, las actitudes obreras que impidan el desarrollo de una vida operante en la industria, la falta de educación social y el escepticismo», lo que habría de contribuir a obtener: el respeto a las medidas preventivas, médicas y de seguridad; la colaboración del capital en materia de control de los riesgos laborales; la disminución de los accidentes, la reducción de la mortalidad; un mayor rendimiento productivo; y un mejor nivel en la actitud física del obrero. ${ }^{34}$ De este modo, la educación sobre higiene y seguridad en el trabajo se vinculaba claramente con las tareas que habrían de permitir, no solo reducir esa siniestralidad laboral y esas enfermedades profesionales que provocaban sufrimiento en los productores y reducían el rendimiento de las empresas, sino también, combatir la conflictividad en el entorno laboral.

En esa misma línea de actuaciones cabe situar la creación de un nuevo organismo en 1956: los Servicios Médicos de Empresa (SME, en

\footnotetext{
${ }_{31}$ El propio Franco inauguró, lo que habla a favor de la importancia que concedía el régimen a las cuestiones relacionadas con la Medicina del Trabajo, unas espléndidas instalaciones que acogían las diferentes secciones del Instituto. «El Instituto Nacional de Medicina del Trabajo», MST 1 (1), (1953): 67-91.

32 «El Instituto Nacional de Medicina y Seguridad del Trabajo. Servicios Generales de Divulgación», MST 1 (4), (1953): 65-71 (p. 65).

33 «El Instituto...Servicios Generales de Divulgación», 67.

${ }_{34}$ «El Instituto...Servicios Generales de Divulgación», 67.
} 
adelante)..$^{35}$ En la exposición de motivos del decreto por el que quedaron establecidos, ${ }^{36}$ se indicaba que «el desarrollo de la industria nacional y el incremento de los riesgos profesionales de los trabajadores, derivados del empleo de nuevas materias primas y de nuevos procesos industriales», exigía crear la figura de los médicos de empresa para «garantizar la defensa de la salud de los que trabajan» y «repercutir favorablemente en el rendimiento y producción de la industria y en la salud de la comunidad nacional». ${ }^{37}$ Los Médicos de Empresa debían de formar parte de los Jurados de Empresa y, entre sus obligaciones y atribuciones, figuraban las relacionadas con: la creación en los productores de un «verdadero sentido de la prevención por medio de los métodos de divulgación adecuados para la formación y enseñanza»; y la orientación de los mismos «en lo relacionado con su salud o la de sus familiares, higiene de la vivienda, higiene individual y familiar». ${ }^{38}$ La importancia que se concedía a su papel en la educación de los trabajadores quedaba reflejada también en los cursos formativos que recibían, que incorporaban contenidos dedicados a la propaganda preventiva y a la higiene y prevención de las enfermedades profesionales y accidentes del trabajo. ${ }^{39}$

El importante apoyo que la Medicina del Trabajo estaba recibiendo por parte del gobierno franquista se expresaba de nuevo con la introducción en las empresas de unos expertos que habían de servir para mejorar las posibilidades de mejorar esos objetivos que tan importantes resultaban para el Gobierno, como era reducir las tasas de siniestralidad laboral y de enfermedades laborales, pero también, con generar una mayor producción e inculcar en los obreros determinadas consignas y valores que el régimen estimaba de gran valor para su legitimación. ${ }^{40}$

\footnotetext{
${ }_{35}$ La actuación tuvo su origen en la recomendación 97, de 1953, de la Oficina Internacional del Trabajo, en la que aconsejaba su creación. José Juan González Sánchez, Seguridad e Higiene en el Trabajo. Formación histórica y fundamentos (Madrid: Consejo Económico y Social, 1977), 151.

36 «Decreto de 21 de agosto de 1956 por el que se organizan los Servicios Médicos de Empresa». BOE 287 (13-octubre-1956): 6497-6498.

37 «Decreto de 21 de agosto de 1956», 6497.

38 «Decreto de 21 de agosto de 1956», 6497.

${ }_{39}$ Cfr. «Programa de los cursos para médicos de empresa», MST 6 (21), (1957): 73-87.

${ }^{40}$ Los SME tuvieron una larga existencia, pues perduraron hasta la década de los noventa en que fueron derogados. Cfr. «Ley 31/1995 de 8 de noviembre de Prevención de Riesgos Laborales», BOE 269 (10-noviembre-1995): 32590-32611, y «Real Decreto 39/1997 de 17 de enero por el que se aprueba el Reglamento de los Servicios de Prevención», BOE 27 (31-enero-1997): 3031-3045. Sobre el
} 
El propio Franco lo destacaba en la clausura del Tercer Congreso Nacional de Medicina del Trabajo. Tras indicar que no existirían "problemas más trascendentales para las clases trabajadoras» que los relacionados con los asuntos tratados en esa reunión científica, señalaba los beneficios que consideraba que se derivarían de la corrección las «consecuencias de la imprevisión»:

Para la Patria, por los bienes que en todos los órdenes se derivan de la prolongación de la vida y bienestar de las familias trabajadoras; para los empresarios, por las mejoras de la rentabilidad, disminución de las cargas y tranquilidad de su conciencia; para los técnicos, por el perfeccionamiento de sus tareas y disminución de sus responsabilidades; y para los obreros y sus familias, por ser los directos y más importantes beneficiarios que se verán redimidos de abandonos seculares, y que es necesario que comprendan que todas estas tareas se derrumbarían si no colaborasen en el mantenimiento de la disciplina y en el cumplimiento de las ordenanzas laborales. ${ }^{41}$

El régimen, por boca de su líder, continuaba poniendo de manifiesto su interés por apoyar a la Medicina del Trabajo, que se había convertido en un vehículo relevante para la «biopolítica» del Nuevo Estado. ${ }^{42}$ En efecto, al haber adquirido los atributos de dos de sus componentes - comportarse como una «disciplina», y como un «dispositivo de

\footnotetext{
desarrollo de los SME véase: Ángel Bartolomé Pineda "Servicios Médicos de Empresa», en Historia de la Medicina del Trabajo en España (1800-2000), eds. Ángel Bartolomé Pineda y cols. (Madrid: MAPFRE, 2004), 617-637.

${ }^{41}$ Cfr. «III Congreso Nacional de Medicina del Trabajo» MST 51 (9), (1957): 104-110 (p. 106).

${ }^{42}$ Michel Foucault desarrolló por primera vez el concepto de «biopolítica» en: Michel Foucault, Histoire de la sexualité 1. La volonté de savoir (Paris: Gallimard, 2003,1976), 177-211; y en Michel Foucault, "Cours du 17 mars 1976», en "Il faut defendre la société». Cours au College de France, 1976 (Paris: Seuil/Gallimard,1997), 213-235. Designó de esa forma a un tipo de poder que hace entrar la vida humana en la «gubernamentalidad», un término que para él no se referiría únicamente al «gobierno» en cuanto al mando y dirección que ejerce el Estado para aplicar su poder sobre los ciudadanos, sino que haría alusión también al modo en que usa para ello la conducta de los individuos. Michel Foucault, «Afterword. The Subject and Power», en Michel Foucault: Beyond Structuralism and Hermeneutics, eds. Hubert L. Dreyfuss and Paul Rabinow (Chicago: Chicago University Press, 1983), 208-226. Sobre la Medicina del Trabajo como parte de la biopolítica del régimen franquista véase: José Martínez-Pérez, «Work, Disability and Social Control: Occupational medicine and Political Intervention in Franco's Spain (1938-1965)», Disability Studies Quarterly 37 (4), (2017). http:// dx.doi.org/10.18061/dsq.v37i4.6098.
} 
seguridad»—, ${ }^{43}$ había pasado a formar parte de aquellos recursos que, al igual que el sistema educativo en su conjunto, contribuyeron a reducir la conflictividad social y a facilitar la perduración del régimen franquista. ${ }^{44}$ No debe extrañar, por tanto, que este continuara estimulando su desarrollo.

En 1959, se procedió a efectuar cambios en la organización de la Medicina del Trabajo. ${ }^{45}$ Se estableció una demarcación de competencias entre tres organismos que quedaban integrados en el INP (Artículo Primero): el Instituto Nacional de Medicina y Seguridad del Trabajo (INMST, en adelante), que fue la nueva denominación que se le confería al INMHST; la Escuela Nacional de Medicina del Trabajo; y la Organización de los Servicios Médicos de Empresa (OSME, en adelante). Con esta última entidad se creaba un organismo destinado a dirigir, coordinar e inspeccionar a los SME,46 a quienes además se procedió a reorganizar también en ese mismo año mediante decreto. ${ }^{47}$ Se pretendía

\footnotetext{
${ }^{43}$ Las «disciplinas» perseguirían dominar las operaciones del cuerpo para lograr el aumento de la utilidad del individuo por medio del control minucioso que ejerciera cada uno sobre sí mismo. Por su parte, los «dispositivos de seguridad» tendrían como objetivo incluir una serie de procesos biológicos de las poblaciones — natalidad, mortalidad, morbilidad, etc.- en el cálculo de gobierno. Salvador Cayuela Sánchez, La biopolítica en la España franquista (Tesis doctoral de la Universidad de Murcia, 2008), 6.

${ }^{44}$ La educación habría formado parte de la gubernamentalidad franquista desempeñando las funciones de inculcar los valores del régimen y facilitar la formación técnica de los futuros profesionales (Salvador Cayuela Sánchez. Por la grandeza de la Patria. La biopolítica en la España de Franco (Madrid: Fondo de Cultura Económica, 2014), 197. En ese sentido, habría contribuido a forjar esa subjetividad, denominada por Cayuela como homo patiens, que caracterizaría a una población sumisa y productiva en lo económico y sometida, resignada y pasiva en lo político (Cayuela, Por la grandeza de la Patria, 207).
}

45 «Decreto 242/1959, de 19 de febrero, sobre reorganización e integración del Instituto Nacional de Medicina y Seguridad del Trabajo en el Instituto Nacional de Previsión», BOE 6 (23-febrero-1959): 3104-3107. La fecha del Decreto estaba mal indicada, era de seis de febrero, como se corrigió con posterioridad ( (Corrección de erratas del Decreto 242/1959 de 19 de febrero sobre reorganización e integración del Instituto Nacional de Medicina y Seguridad del Trabajo en el Instituto Nacional de Previsión», BOE 52 (2-marzo-1959): 3517.

${ }^{46}$ Las misiones que se le encomendaban eran: proceder al informe, estudio y clasificación de los SME; inspeccionarlos y vigilarlos; conocer las vacantes que se produjeran e intervenir en los nuevos nombramientos de médicos de empresa; y realizar los proyectos de modificaciones reglamentarias que afectaran a los SME. «Orden de 8 de abril de 1959 por la que se desarrolla lo dispuesto en el Decreto 242/1959 sobre la organización de los Servicios Médicos de Empresa», BOE 93 (18-marzo-1959): 5806-5807 (p. 5806).

47 «Decreto 1036/1959, de 10 de junio, por el que se reorganizan los Servicios Médicos de Empresa», BOE 148 (22-junio-1959): 8873- 8875 (p. 8873). Sobre el desarrollo de la OSME véase: Ángel Bartolomé Pineda, «Organización de los Servicios Médicos de Empresa», en Historia de la Medicina del Trabajo en España (1800-2000), eds. Ángel Bartolomé Pineda y cols. (Madrid: MAPFRE, 2004), 603-616. 
conseguir que los "objetivos de medicina preventiva» que se asignaban a los SME se extendieran a un número más amplio de trabajadores. ${ }^{48}$ Las funciones asignadas a los médicos de empresa no se vieron, sin embargo, sustancialmente modificadas en relación con las que se hallaban ya establecidas, ${ }^{49}$ y la educación de los trabajadores en materias relacionadas con la conservación de la salud continuó formando parte de sus competencias. ${ }^{50}$

La OSME, sobre todo inicialmente, desempeñó un papel destacado en la tarea de conseguir que los SME pudieran implantarse en nuestros talleres y fábricas. ${ }^{51} \mathrm{~A}$ juicio de un destacado médico de empresa, esta labor habría servido, entre otras cosas, para: generar en España «una concienciación social» de la necesidad de llevar a cabo «actuaciones preventivas laborales encaminadas a evitar los riesgos del trabajo y mejorar la salud y seguridad de los trabajadores»; conseguir una «rápida difusión de la Medicina del Trabajo como Especialidad Médica»; y desplegar así una tarea de «educación higiénico preventiva de los trabajadores».52

De este modo, el período del que me he ocupado en este apartado se mostró muy propicio y provechoso para que la Medicina del Trabajo

\footnotetext{
${ }^{48}$ En el artículo segundo del Decreto se ordenaba que las empresas con una plantilla superior a mil trabajadores establecieran obligatoriamente los SME, y que las que tuvieran un número inferior a mil y superior a cien trabajadores constituyeran en un plazo de un año agrupaciones para su establecimiento.

49 En 1959 se publicó también el reglamento de los SME. «Orden de 21 de noviembre de 1959 por la que se aprueba el Reglamento de los Servicios Médicos de Empresa». BOE 284 (27-noviembre-1959): $15150-15158$.
}

${ }^{50}$ La función de «educación higiénico-preventiva de los trabajadores» incluía labores de: divulgación entre los productores de los conocimientos necesarios para la prevención de enfermedades y accidentes; organización de concursos, competiciones, conferencias, reuniones, etc., destinadas a mantener e incrementar la formación preventiva de los trabajadores; y colaboración con las autoridades sanitarias en las campañas de educación preventiva (Art. sexto).

${ }^{51}$ Bartolomé Pineda, «Organización de los Servicios Médicos de Empresa», 615. En 1963 habría un total de 1.896 SME, establecidos en 3.449 empresas, que cubrían a 1.293.287 trabajadores. Para 1968, 2.727 SME se repartirían entre 4.417 empresas para atender a 1.718.097 productores. En 1980, 2.086.946 trabajadores se encontraban bajo alguno de los 3.996 SME que realizaba su labor en alguna de las 6.251 empresas que contaban con ellos. Cfr. Bartolomé Pineda, "Servicios Médicos de Empresa», 627.

52 Bartolomé Pineda, «Servicios Médicos de Empresa», 631-632. Ángel Bartolomé Pineda fue Presidente de la Sociedad Castellana de Medicina y Seguridad del Trabajo y de la Sociedad Española de Medicina y Seguridad del Trabajo. Manuel Rodríguez Carmona, «Prólogo», en Historia de la Medicina del Trabajo en España (1800-2000), eds. Ángel Bartolomé Pineda y cols. (Madrid: MAPFRE, 2004): XXIII-XXXII (p. XXIII). 
pudiera consolidarse como especialidad.53 Había permitido establecer con el INMHST un marco institucional adecuado para su desarrollo técnico. Además, la creación de la Escuela Nacional de Medicina del Trabajo sirvió para generar una estructura educativa que facilitó la formación de nuevos expertos - los médicos de empresa - encaminados a procurar inculcar en los productores la importancia de prevenir la siniestralidad y las enfermedades profesionales para potenciar así el crecimiento económico. ${ }^{54}$ Así las cosas, los especialistas iban a organizarse, constituyendo la Sociedad Española de Medicina del Trabajo, ${ }^{55}$ con el objetivo de tratar de mejorar su capacidad de respuesta para responder a lo que se esperaba de ellos introduciendo novedades en su modo de concebir su disciplina. Como veremos a continuación, eso iba a favorecer una mayor preocupación por educar a los productores en relación con la higiene y seguridad en el trabajo.

\section{CAMBIOS EN LA MEDICINA DEL TRABAJO}

En la década de los sesenta la Medicina del Trabajo dio claras muestras de interés por inducir cambios en su modo de considerar la manera en que debía de operar para lograr hacer más seguros y saludables esos espacios - fábricas, talleres, minas, obras, oficinas...- donde nos acechan y atacan — sigilosos, oportunistas e incansables- los accidentes y las enfermedades laborales. La reflexión de los expertos sobre los contenidos de su disciplina iba a suponer una renovación en el modo en que se plantearon la forma de abordar el problema de controlar las

\footnotetext{
${ }_{53}$ Para el desarrollo de la Medicina del Trabajo en España puede verse: Bartolomé Pineda, Historia; y Alfredo Menéndez Navarro y Esteban Rodríguez-Ocaña. «From "Accident Medicine" to "Factory Medicine": Spanish Occupational Medicine in the Twentieh Century», en Origins of Occupations Health Associations in the World, eds. A. Grieco, D. Fano, T. Carter, S. Iavicoli (Amsterdam: Elsevier, 2003), 207-216.

${ }_{54}$ Ya en el primer curso se incorporó en el temario una sesión sobre «Métodos de divulgación en medicina del trabajo». Cfr. «Información del Instituto. Cursillo de Medicina del Trabajo para médicos de empresa» MST 3 (12), (1955): 95-97 (p. 96). El primero de los cursos se desarrolló en Madrid en 1955. Dos años más tarde se celebraron ya tres cursos, que contaron con 106, 104 y 106 participantes. A partir de 1959 los cursos se empezaron a multiplicar, realizándose en Madrid y Barcelona todos los años, y se extendieron rotativamente a otras capitales de provincia. Eduardo Mascías. «Escuela Nacional de Medicina del Trabajo», en Historia de la Medicina del Trabajo en España (18002000), eds. Ángel Bartolomé Pineda y cols. (Madrid: MAPFRE, 2004), 759-769 (p. 763).

${ }_{55}$ Cfr. «Constitución de la Sociedad Española de Medicina del Trabajo». MST 4 (16), (1956), 73-76. Sobre esta asociación puede verse: Ángel Bartolomé Pineda, «Sociedad Española de Medicina del Trabajo». En Historia de la Medicina del Trabajo en España (1800-2000), eds. Ángel Bartolomé Pineda y cols. (Madrid: MAPFRE, 2004), 639-684.
} 
amenazas a la salud de los trabajadores. Debo matizar: en realidad, más que de una renovación, se trató de realizar un ajuste que, en conformidad con las consignas e ideas que se venían propugnando con anterioridad desde organismos internacionales, conducía a priorizar determinadas parcelas de las tradicionalmente cultivadas por la Medicina del Trabajo. Tampoco se trató de un cambio drástico, sino más bien, progresivo. Como veremos, el resultado iba a ser que la actividad asistencial, la recuperación quirúrgica y médica de los trabajadores, que había sido uno de los componentes más característicos de la disciplina y que había contribuido significativamente a la legitimar la labor de quienes la cultivaban, ${ }^{56}$ iba a ceder frente a las prácticas preventivas. ${ }^{57}$ Con ello, la labor pedagógica sobre los productores fue, como veremos, adquiriendo un espacio más amplio y relevante entre las medidas que los especialistas en Medicina del Trabajo encontraron oportuno promover para reducir los riesgos que para la salud lleva aparejada la actividad laboral.

Hay que tener en cuenta que, ya desde mediados de la década de los cincuenta, se aprecia una preocupación por el incremento de los accidentes del trabajo y las enfermedades profesionales. ${ }^{58}$ La inquietud parece que estaba justificada. Aunque se ha hablado de la existencia de una "opacidad estadística» para el caso de la siniestralidad laboral hasta 1955, en que se habría intentado establecer un procedimiento más fiable para recoger los datos, ${ }^{59}$ a partir de ese año los accidentes del trabajo experimentaron un crecimiento significativo. Si en 1954 su número era de

\footnotetext{
56 Para el caso español puede verse: José Martínez-Pérez, «El obrero recuperado: Medicina del Trabajo, Ortopedia y el impacto de la tecnología médica sobre la imagen social de las personas con discapacidades (España, 1922-1936)», História, Ciencias, Saúde - Manguinhos 13 (2006): 349-373.

57 Sobre este cambio véase: José Martínez-Pérez, «Reforma sanitaria e introducción de una nueva cultura de la salud en España: acerca del discurso sobre Medicina, Higiene y Seguridad en el trabajo (1940-1982)», en Genealogías de la reforma sanitaria en España, eds. José Martínez-Pérez y Enrique Perdiguero-Gil (Madrid; Catarata, 2020), 215-239.

${ }_{58}$ Fernández Gómez, De la Guerra Civil, 95. Este autor atribuye este incremento a la intensificación del proceso industrializador, que habría favorecido el paso de la población agrícola activa hacia la construcción y la industria, y al hecho de que ese colectivo estuviera constituido por jóvenes «sin formación profesional adecuada».

59 Jerònia Pons-Pons y Margarita Vilar-Rodríguez, La gestión del Seguro de Accidentes en España: de Mutuas Patronales a entidades colaboradoras de la Seguridad Social, 1900-2019 (S.l.: Ministerio de Inclusión, Seguridad Social y Migraciones - Editorial MIC, 2020), 23. Estas autoras señalan que las cifras de accidentes del trabajo disponibles, especialmente hasta mediados de la década de los cincuenta, ofrecerían una escasa credibilidad, que se reconocería en el propio $B O E$.
} 
500.805, en 1958 se contabilizaron ya 1.002.129, y, sin caer por debajo de los 900.000 en los años siguientes, en 1963 se registraron 1.008.850.60

Estas alarmantes cifras, con el consiguiente coste económico, ${ }^{61}$ recomendaban desde luego la adopción de iniciativas en orden a mejorarlas. Entre ellas, la prevención y actuación sobre el que denominaban «factor humano». Esta toma de posición de la Medicina del Trabajo estaba motivada por el modo en que se había modificado la concepción de la disciplina. En 1950 un Comité Mixto de la Organización Mundial de la Salud (OMS, en adelante) y la Organización Internacional del Trabajo (OIT, en adelante) decidió adoptar la siguiente definición para la disciplina:

La «medicina del trabajo» tiene como finalidad fomentar y mantener el más elevado nivel de bienestar físico, mental y social de los trabajadores; prevenir todo daño causado a la salud de estos por las condiciones de su trabajo; protegerlos en su empleo contra los riesgos resultantes de la presencia de agentes nocivos para la salud; colocar y mantener al trabajador en un empleo que convenga a sus aptitudes fisiológicas y psicológicas, y en suma, adaptar el trabajo al hombre y el hombre a su trabajo. ${ }^{62}$

De este modo, la ruta por la que se recomendaba que debía avanzar la Medicina del Trabajo situaba a la actividad asistencial en una vía secundaria. ${ }^{63} \mathrm{La}$ intervención curativa y rehabilitadora, que tanto había

\footnotetext{
${ }^{60}$ Pons-Pons y Vilar-Rodríguez, La gestión del Seguro, 125-126. Estas autoras atribuyen este incremento no solo a la mejora en la recolección de datos, sino también, a la unificación de las mutualidades agrarias e industriales, que se pudo traducir en una mayor declaración de siniestros (p. 148).

${ }^{61}$ Un estudio realizado en 1959 sobre 4.030 accidentes atribuía, según el método de análisis empleado, un coste de 32.294.749,42 pesetas (con un costo medio directo de 7.997 pesetas) o de 161473.746 pesetas (con un coste medio total de 39.998 pesetas por accidente). J. Álvarez Muñiz y R. Riccardi, «El costo de los accidentes de trabajo en España», MST 8 (31), (1960): 17-23 (p. 20).

${ }^{62}$ Cfr. Comité Mixto OIT/OMS sobre Higiene del Trabajo. Tercer Informe. Organización Mundial de la Salud. Serie de Informes Técnicos. Número 135 (Ginebra: Organización Mundial de la Salud, 1957), 4. Disponible en http://www.who.int/iris/handle/10665/37336. Consultada el 15 de abril 2019.

${ }_{63}$ Acerca del papel de diferentes organismos internacionales, especialmente la OIT, y sobre las diferentes fuerzas que operaron sobre él, véase: Thomas Cayet, Paul-André Rosental y Marie Thébaud-Sorger, «How International Organisations Compete: Occupational Safety and Health at the ILO, a Diplomacy Expertise», Journal of Modern European History 2 (2009):174-195; y Joseph Melling y Christopher Sellers, «Objetive Collectives? Transnationalism and "Invisibles Colleges" in Occupational and Environmental Health from Collis to Selikoff», en Dangerous Trade. Histories of Industrial Hazards across a Globalizing World, eds. Christopher Sellers y Joseph Melling (Philadelphia, Pennsylvania: Temple University Press 2012), 113-125.
} 
contribuido a legitimar a la disciplina y a sus cultivadores, quedaba desplazada por esa toma de posición favorable a la prevención y a la intervención sobre el trabajador para mantener su salud.

Los expertos españoles reaccionaron favorablemente a esa propuesta. Uno de ellos indicaba ya en 1954 que no bastaban «las clínicas lujosas y los médicos abnegados luchando contra el dolor» para combatir los riesgos laborales, sino que era "preciso evitar que la enfermedad profesional o el accidente laboral sean como una espada de Damocles suspendida sobre la cabeza del trabajador». ${ }^{64}$ En 1961, tomando como referencia la definición del Comité Conjunto de la OMS y la OIT, otro especialista caracterizaba la disciplina como una Medicina protectora de la salud de los trabajadores, preferentemente preventiva. ${ }^{65}$ Para él, en la Medicina del Trabajo la actuación terapéutico-curativa sería «solo circunstancial y periférica, no esencial», y la labor asistencial en el propio ambiente del trabajo representaría «el fracaso de la disciplina». ${ }^{66} \mathrm{En}$ ese mismo año podía leerse también en España que la disciplina debía de ocuparse en ese momento, "con el más profundo énfasis», de «lograr proteger y mejorar la salud de los trabajadores». ${ }^{67}$ Según indicaba un autor, cuanto se hiciera "en beneficio de la conservación de la salud» y de incrementar «la capacidad de trabajo» sería una inversión rentable. ${ }^{68}$

El viraje en España de la Medicina del Trabajo hacia una orientación más preventiva se aprecia también en los contenidos de sus reuniones científicas. En 1957, el Tercer Congreso Nacional de la disciplina dedicó

${ }^{64}$ A. Millor Arregui, «La Medicina del Trabajo y la Seguridad en el mismo», MST 2 (7), (1954): 69-71 (p. 71).

${ }_{65}$ M. Baselga Monte, «Medicina del Trabajo y Medicina de Empresa», MST 9 (35), (1961): 73-87 (p. 74). Sobre este médico véase: F. G. Benavides, «Manuel Baselga, defensor de la salud de los trabajadores»,ElPaís (24junio 2009).https://elpais.com/diario/2009/06/24/necrologicas/1245794401_850215. html. Consultada el 11 de abril de 2021; y Jacint Corbella, «Obituario. Un pionero de la medicina del trabajo. Manuel Baselga Monte (1931-2009) Médico», La Vanguardia (28 junio 2009). http://hemeroteca.lavanguardia.com/preview/2009/06/18/pagina-35/78239960/pdf.html (consultado el 11-4-2021).

${ }^{66}$ Baselga Monte, «Medicina del Trabajo y Medicina de Empresa», 74.

${ }^{67}$ I. Urbandt, «Prevención de riesgos profesionales en relación con el factor humano» MST 9 (41), (1961): 37-43 (p. 39). También se expresaban en ese sentido Malboysson y Bonell, para quienes la Medicina del Trabajo debía ser considerada más que una especialidad, pues se trataría de toda la Medicina «aplicada a una sola finalidad: la de proteger al hombre de los peligros que para su salud se derivan del trabajo». E Malboysson y A. Bonell, «El médico de empresa y la prevención» MST 10 (37), (1962): 36-47 (p. 37).

${ }^{68}$ C. Soler Doppf, «El porvenir de la Medicina del Trabajo» MST 11 (43), (1963): 37-43 (p. 43). 
todavía secciones a la Patología Médica y a la Quirúrgica, aunque ya empezaban a cobrar relevancia los aspectos relacionados con la higiene y seguridad (tres secciones) y con el rendimiento y la Psicología Industrial (dos secciones). ${ }^{69}$ Los aspectos clínicos y asistenciales quedaban ya muy relegados en el Cuarto Congreso, ${ }^{70}$ celebrado en 1965, y en el Quinto. En este último, que tuvo lugar en 1966 y contó con alrededor de mil participantes, las tres sesiones plenarias se dedicaron a: los protagonistas de la Seguridad Social y de la higiene en el seno de las empresas; las técnicas de Seguridad e Higiene del Trabajo; y la presencia de la seguridad y de la higiene a través de organismos extra-empresariales. Además, entre las veintitrés mesas redondas que se consideró que funcionaron con eficacia, solo cinco se dirigieron a tratar temas clínicos y asistenciales, que cedieron ante otros, como el de la educación para la seguridad e higiene del trabajo, que se encontraban relacionados con la prevención de los riesgos laborales. ${ }^{71}$ De hecho, entre las conclusiones generales aprobadas por el pleno del Congreso figuró la de que se hiciera obligatoria la «enseñanza de la Higiene y Seguridad del Trabajo en la enseñanza primaria, media, superior, profesional y técnica». ${ }^{72}$

Al lado de este refuerzo de la vertiente preventiva de la disciplina, la orientación hacia la consideración del «factor humano» se vio también vigorizada. Al ocuparse de las orientaciones modernas de la Medicina del Trabajo, un destacado experto señalaba que habían quedado atrás dos fases de la disciplina —la reglamentista y la de improvisación-, para dar paso a las de estudio científico (clínico, físico, químico) y del «factor humano». ${ }^{73}$

\footnotetext{
${ }^{69}$ Cfr. «III Congreso Nacional», 107.

${ }^{70}$ Entre los nueve temas que se propusieron para el debate, tan solo uno - neumoconiosis por polvos vegetales - cabe incluirse entre los que podían contener aspectos clínicos y asistenciales. $C f r$. «IV Congreso Nacional de Medicina y Seguridad del Trabajo», MST 13 (49), (1965): 77.

${ }^{71}$ Cfr. J. Dantín Gallego, «V Congreso Nacional de Medicina y Seguridad del Trabajo» MST 15 (57), (1967): 86-107 (pp. 86-87).

72 Dantín Gallego, «V Congreso», 90.

73 Juan Dantín Gallego, «Orientaciones modernas para la Medicina del Trabajo» MST 11 (36), (1961): 45-51 (p. 45). Una semblanza de este médico, uno de los más activos impulsores de la disciplina en la España de la postguerra, es la ofrecida por: P. Sangro, «El Dr. Dantín Gallego cumple 70 años», MST 24 (95), (1976): 5-14.
} 
La actuación sobre el llamado "factor humano» se ubicaba así en una posición destacada en la labor de reducir las tasas de accidentes y enfermedades laborales. Los expertos españoles se situaban de esta manera en línea con lo que se estaba sosteniendo en las reuniones científicas internacionales. En el Tercer Congreso Mundial de Prevención de los Riesgos Profesionales se planteó que, debido a los progresos realizados por la tecnología, solo un veinticinco por ciento de los accidentes tendría su origen en imperfecciones técnicas o de organización, mientras que el setenta y cinco por ciento restante sería «imputable a los factores humanos dependientes de las propias víctimas o sus colaboradores». ${ }^{74}$ Esa misma idea, se defendía en las páginas de la revista del INMST. En ellas, se planteaba que, aun cuando a menudo concurren en el accidente causas físicas o ambientales y causas humanas, el «factor humano» sería el preponderante en el ochenta y ocho por ciento de los casos. ${ }^{75}$

La nueva perspectiva por la que pretendía encauzar su macha la Medicina del Trabajo favorecía que la educación del obrero en higiene y seguridad de trabajo fuera contemplada como una herramienta importante al objeto de mejorar las posibilidades de reducir la siniestralidad y las enfermedades laborales. En el Cuarto Congreso Internacional de Prevención de Riesgos Profesionales, celebrado en Londres en 1964, se sostuvo que era «de suma importancia educar al hombre sobre las condiciones del trabajo», tarea a cuya vanguardia se hallaría la Ergonomía; y se ubicaba esa necesidad en consonancia con la definición de la Medicina del Trabajo y del Comité Conjunto de la OMS y de la OIT en la que se señalaba su función de adaptar el trabajo al hombre y a cada hombre a su tarea. ${ }^{76} \mathrm{La}$ importancia de fortalecer la educación para reducir los accidentes del trabajo era también señalada por el Director General de la OMS, para quien sería en ella donde residiría la «esperanza más fundada de poder prevenirlos». ${ }^{77}$

\footnotetext{
${ }^{74}$ Cfr. R. Cortés Gallego, «Tercer Congreso Mundial de Prevención de los Riesgos Profesionales», MST 10 (38), (1962): 64-73 (p. 69).

${ }^{75}$ A. Ruiz Salazar, «El factor humano como agente causal del accidente laboral», MST 14 (56): 39-49 (p. 40).

${ }^{76}$ Cfr. V. M. Llinares, «IV Congreso Internacional de Prevención de Riesgos Profesionales» MST, 13 (49), (1965): 62-67 (p. 63).

77 Cfr. A.F., «La gran importancia del accidente», MST 10 (38), (1962): 98-99 (p. 98).
} 
En línea con esta posición, dentro de nuestras fronteras se iba a plantear que, dado que un setenta por ciento de los accidentes serían «a causa del sujeto», se imponía «la responsabilización de los individuos en sus actos y en sus sistemas de trabajo». Para lograrlo, era preciso instruir al trabajador en la necesidad de una seguridad que habría de darle a conocer los peligros y los medios para evitarlos, lo que debía conseguirse «no por imposición, sino por persuasión».78 Para instigar al obrero a «activar el estímulo a protegerse» había que impartir conferencias, proceder a la divulgación de los principios de seguridad mediante las revistas de las empresas o de los sindicatos, crear pequeños textos de enseñanza fácil y clara exposición para la enseñanza de los productores, o poner en marcha sistemas de propaganda basada en la intervención de los productores con artículos y sugerencias. ${ }^{79}$

Esta labor se estaba realizando ya en algunas empresas. En Hidroeléctrica Española, el adiestramiento del obrero en materia de seguridad se iniciaría «desde el mismo instante en que comienza su trabajo». Los médicos de la empresa trataban de desarrollar en el trabajador «el espíritu de seguridad». Para ello, impartieron 31 cursos de formación dirigidos a los denominados «monitores de seguridad». Se esperaba que estos tutores contribuyeran a: desarrollar en todos los trabajadores la idea de prevención; instruir al personal para que conociese las medidas a tomar encaminadas a disminuir los riesgos colectivos e individuales; generalizar la enseñanza de la seguridad en todos los empleados; conocer los riesgos inherentes a las diversas tareas; y divulgar las normas a seguir ante un accidente..$^{80}$ Además, la educación en materia de higiene y seguridad en el trabajo se fomentaría mediante la divulgación con carteles y folletos, y con su enseñanza en las escuelas de formación profesional de la empresa. ${ }^{81}$

La prevención, y la actuación educativa sobre el obrero en materia de profilaxis de la siniestralidad laboral y de las enfermedades profesionales, había cogido aliento dentro de nuestras fronteras. Prueba de ello fue

\footnotetext{
${ }_{78}$ V. Barberá, «La prevención en el trabajo» MST 17 (65), (1969): 40-52 (p. 49).

79 Barberá, «La prevención», 51.

${ }^{80}$ Malboysson Corrocher, et al., «La Medicina de Empresa en Hidroeléctrica Española, S. A.». MST 11 (42), (1963): 48-81 (pp. 64-65).

${ }^{81}$ Malboysson Corrocher, et al., «La Medicina de Empresa», 70-71.
} 
la Campaña Nacional de Prevención de Accidentes del Trabajo, celebrada en 1966, en la que se ha advertido la presencia de una marcada atención hacia los métodos relacionados con la actuación sobre el «factor humano». ${ }^{82}$ Entre estos, la propaganda, con el uso de carteles como principal elemento para llevarla a cabo, iba a ser un recurso especialmente atendido. En efecto, desde el INMST se estimuló notablemente su aplicación como una herramienta eficaz en la tarea de inculcar en los productores, por razones humanitarias y de mejora de la producción, la necesidad de evitar los riesgos laborales. ${ }^{83}$ La propaganda permitiría "poner de manifiesto la utilidad y conveniencia de las normas de seguridad», y señalar los procedimientos más oportunos para tratar de «vencer la apatía y el desprecio del obrero» $\mathrm{y}$ «la despreocupación de las empresas» por estos problemas. ${ }^{84}$ Los procedimientos de que dispondría ese «medio educativo por el cual el obrero puede alcanzar el sentido de seguridad» — carteles, conferencias, folletos, concursos periódicos murales, altavoces, cursos breves...-, serían herramientas que servían para combatir un rasgo que se atribuía a los obreros: su actitud indolente hacia los riesgos del trabajo. Según se mantenía, los trabajadores mostrarían una tendencia a «despreocuparse de toda norma de seguridad», por lo que los procedimientos a emplear debían tender a tratar de vencer esta indiferencia llamando su atención sobre el problema, para conseguir inculcarle ese «sentido de responsabilidad o de prudencia, del que la mayoría de los casos carece». .85

No debe extrañar que un curso que se propuso para la formación en seguridad de los obreros dedicara cuatro de sus cinco sesiones a:

\footnotetext{
82 Agustín Galán García y Mónica Ortega Moreno, «La construcción del relato preventivo en España durante el siglo XX», Revista Internacional y Comparada de relaciones laborales y derecho del empleo, 5 (3), (2017). http://ejcls.adapt.it/index.php/rlde_adapt/article/view/533/725 (consultado el 11-4-2021)

83 A. Álvarez y E. Cerra, «Conceptos básicos de la propaganda preventiva», MST 8 (32), (1960): 18-30 (p. 19). En la década de los sesenta estos autores, miembros del Servicio de Divulgación del INMST, publicaron sucesivos trabajos en MST dedicados a defender el valor de la propaganda como forma de educar al trabajador, y a los métodos para llevarla a cabo: A. Álvarez y E. Cerra, «Consideraciones generales para el planteamiento de una campaña de propaganda preventiva», MST 9 (33), (1961): 3-61; A. Álvarez y E. Cerra, «La propaganda preventiva y la organización de campañas de seguridad en la industria», MST 9 (35), (1961): 52-59; A. Álvarez, «La propaganda preventiva como factor indispensable en la empresa», MST 10 (37), (1962): 48-52; A. Álvarez, "Campañas de seguridad en los trabajos agrícolas», MST 15 (60), (1967): 5-13; A. Álvarez, «La propaganda preventiva en los trabajos de construcción», MST 16 (64), (1968): 73-76.
}

${ }^{84}$ A. Álvarez y E. Cerra, «Consideraciones generales», 53.

${ }^{85}$ A. Álvarez y E. Cerra, «Consideraciones generales», 56. 
1) poner de manifiesto los perjuicios que ocasionan los accidentes, que trataba de «tocar la fibra sensible y emotiva» de los obreros, «recalcar que el más perjudicado es el accidentado y su familia», y señalar el coste de los accidentes para la nación; 2) demostrar que los accidentes «tienen una causa y que esta causa depende de nosotros mismos», en que se destacaban como causas del accidente las relacionadas con el «factor humano» (distracciones, desconocimiento del trabajo, falta de facultades físicas, falta de prendas de protección, uso de herramientas en mal estado o inadecuadas, o trabajar en zonas prohibidas); 3) Señalar lo que cada obrero puede hacer para evitar accidentes; y 4) Recalcar que es posible acostumbrarse a hacer las cosas bien. ${ }^{86}$ El curso finalizaría haciendo hincapié en poner de relieve que la seguridad: sería un asunto personal; pediría una acción individual; que la decisión de ser seguro dependería del obrero; y que ser un «hombre seguro» sería, en gran medida, una cuestión de acostumbrarse a serlo.

De este modo, el tipo de aproximación al abordaje de los problemas derivados de los riesgos laborales que se estaba impulsando en España pasaba por adoctrinar al obrero en esa idea de que las víctimas de los accidentes y las enfermedades profesionales eran en gran medida responsables de la pérdida de su salud. La enseñanza de la higiene y seguridad en el trabajo era interpretada como un modo de trasladar al trabajador esa tendencia, muy extendida como vimos arriba entre los que cultivaban la Medicina del Trabajo, de que buena parte de la responsabilidad de la mayor parte de los accidentes laborales habría que atribuirla a los propios obreros. Su educación en esas materias poseía así un componente de alto alcance: el de inducir en los trabajadores un sentimiento de culpabilidad ante la producción de un accidente o la aparición en ellos de enfermedades profesionales.

Es conveniente señalar que, a pesar de la preponderancia dada a la prevención, el componente clínico y asistencial continuaba figurando en el marco de estrategias que los expertos proponían para la estructura de la Medicina del Trabajo. ${ }^{87}$ No obstante, las actuaciones que se llevaron a cabo por el gobierno en esa década, encaminadas a crear una

\footnotetext{
${ }^{86}$ Cfr. A. Ilarduya, «Curso de formación en seguridad de obreros», MST 12 (45), (1964): 77-79.

${ }^{87}$ Cfr. J. Dantín Gallego, «Plan de conjunto para la organización de la Medicina del Trabajo», MST 12 (46), (1964): 80-83.
} 
organización asistencial para los trabajadores —Ley de Bases de la Seguridad Social (1966), aprobación de su articulado (1966) y publicación de un decreto dirigido a establecer normas sobre las prestaciones de asistencia sanitaria que se situaban bajo el régimen de la Seguridad Social (1967) — ${ }^{88}$ contribuyeron a ahondar en ese alejamiento de la Medicina del Trabajo de su contenido clínico y asistencial. ${ }^{89}$

A finales de la década de los sesenta, la confianza en la perspectiva preventiva para abordar el problema de los riesgos laborales fue cuestionada. No se trataba tanto de que se pusiera en duda su capacidad para combatir los accidentes del trabajo o las enfermedades profesionales, sino del método que se seguía en España para su aplicación. Según afirmaba un experto, hacia 1968 "nos hallaríamos inmersos en un ambiente general nacional favorable para la seguridad $»,{ }^{90}$ que era necesario mantener. Para ello, era preciso que la aplicación de los métodos que se estaban proponiendo desde la Medicina del Trabajo se hiciera correctamente. Una serie de «mitos» estarían dificultando esa labor. ${ }^{91}$ Entre ellos se hallaría el relativo al "factor humano». Aunque admitía el lugar relevante de éste en la etiología de la siniestralidad laboral, se manifestaba, sin embargo, favorable a potenciar, frente a las estrategias preventivas destinadas a actuar sobre él, la actuación técnica sobre el ambiente que rodea al productor en su trabajo. Para argumentarlo, afirmaba que la única manera de influirle "humana, digna, profunda y permanentemente es a través de las técnicas de educación», pero que ello supondría invertir mucho tiempo y dinero sin tener la absoluta certeza de conseguir resultados eficaces. ${ }^{92}$

\footnotetext{
88 «Ley 1993/1963 de 28 de diciembre sobre Bases de la Seguridad Social», BOE 312 (30-diciembre-1963): 18181-18190; «Decreto 907/1966 de 21 de abril aprobando el texto articulado primero de la Ley 193/1963 de 28 de diciembre sobre Bases de la Seguridad Social». BOE 96-97 (22 y 23-abril-1966): 4778-4869; «Decreto 909/1966 de 21 de abril aprobando el texto articulado segundo de la Ley 193/1963 de 28 de diciembre sobre Bases de la Seguridad Social». BOE 97 (23-abril-1966): 4869-4888; «Decreto 2766/1967, de 16 de noviembre, por el que se dictan normas sobre prestaciones de asistencia sanitaria y ordenación de los servicios médicos en el Régimen General de la Seguridad Social», BOE 284 (28-noviembre-1967): 16425-16430.

89 Véase al respecto: Martínez-Pérez, «Reforma sanitaria», 225-226.

${ }^{90}$ M. Baselga Monte, «Los mitos de la seguridad». MST XVI (62- 63), (1968): 16-35 (p. 17).

${ }^{91}$ Baselga, «Los mitos», 20

${ }_{92}$ Baselga, «Los mitos», 21-22.
} 
A pesar de opiniones como ésta, la Medicina del Trabajo continuó concediendo a la educación sobre aspectos relacionados con la higiene y seguridad en el trabajo un lugar destacado en las estrategias destinadas a reducir la siniestralidad laboral y las enfermedades profesionales. Como intentaré poner de manifiesto a continuación, el giro operado en la disciplina hacia la prevención de los riesgos del trabajo, con el consiguiente refuerzo del papel de su enseñanza entre los productores para desarrollar en ellos un sentido de la responsabilidad, iba a constituir un ingrediente destacado de las recetas que se iban a proponer en la España de la década de los setenta para conservar la salud de los productores.

\section{NUEVOS MARCOS ORGANIZATIVOS PARA LA MEDICINA DEL TRABAJO Y CONSOLIDACIÓN DE UNA TENDENCIA (1970-1975)}

El crecimiento de la actividad industrial durante la etapa del desarrollismo provocó a su vez un incremento de la preocupación por los riesgos laborales. Se hablaba de la existencia de un ascenso en las tasas de accidentes y, a menor escala, de las enfermedades profesionales, lo que hizo pensar en la necesidad de introducir medidas para tratar de reducirlas. ${ }^{93}$ Expresión de ello fue una orden de 7 de abril de 1970 con la que se quería comenzar a cumplir con lo establecido en Ley de la Seguridad Social respecto a los cometidos del Servicio Social de Higiene y Seguridad del Trabajo, ${ }^{94}$ que comprenderían las normas técnicas y medidas sanitarias de tutela dirigidas a: eliminar o reducir los riesgos de los distintos centros y puestos de trabajo; estimular y desarrollar en las personas una actitud positiva y constructiva respecto a la prevención de los accidentes y enfermedades que pudieran derivarse de su actividad

\footnotetext{
93 Alfredo Menéndez Navarro, «Médicos, medicina y salud laboral en España. Una mirada constructivista al abordaje de las enfermedades profesionales, 1900-1975», La Mutua 18 (2007): 171-189 (p. 186). Los expertos indicaban que en 1965 se había producido un incremento de la siniestralidad del diez por ciento, (Baselga, «Los mitos», 19), y que de 522.350 accidentes en 1955 se habría pasado a 1.099.637 en 1967; Narciso Perales Herrero, «Problemática de la medicina y seguridad del trabajo», en Tratado de Higiene y Seguridad del Trabajo, eds. Narciso Perales Herrero (Madrid: Ministerio del Trabajo, 1971), 19-35. (Cfr. Menéndez Navarro, «Médicos, medicina», 186.). Un estudio reciente, que advierte sobre la posible falta de fiabilidad de los datos suministrados por las fuentes estadísticas consultadas, señala que entre 1957 y 1975 la cifra se habría mantenido en torno al millón de accidentes anuales. Pons-Pons y Vilar-Rodríguez, La gestión, 241.

${ }_{94}$ Los decretos por los que se aprobó en 1966 el articulado de la Ley de Bases de la Seguridad Social, plantearon que la acción protectora del sistema de la Seguridad Social comprendería la dispensada por los «Servicios Sociales», que inicialmente incluirían los de: Higiene y Seguridad del Trabajo; Medicina Preventiva; Recuperación de Inválidos; y Acción Formativa. «Decreto 907/1966», 4781-4782.
} 
profesional; y lograr, individual o colectivamente, un óptimo estado sanitario. ${ }^{95}$ Dada la amplitud de su ámbito, se consideraba ineludible proceder a la elaboración de un Plan Nacional de Higiene y Seguridad en el Trabajo (PNHST, en adelante) al que, de manera progresiva, deberían ajustarse los cometidos, funciones y actividades que habían sido asignadas al Servicio Social. ${ }^{96}$ Con la creación en 1970 del Consejo Superior de Higiene y Seguridad del Trabajo, se generó un órgano destinado a facilitar la elaboración del PNHST y su supervisión. ${ }^{97}$ Su Secretaría Técnica sería la encargada de, entre otras cosas: vigilar el cumplimiento y eficacia del Plan; estudiar las necesidades en materia de seguridad e higiene del trabajo y formular las correspondientes propuestas al respecto; y programar los cursos formativos de prevención, seguridad e higiene..$^{98}$

$\mathrm{Al}$ cierre, por tanto, de la década de los sesenta, la vertiente preventiva, y la educación frente a los riesgos laborales, recibía aliento por parte del régimen franquista. La reducción de los riesgos del trabajo continuaba representando para él una «sangría abierta de vidas, energía y recursos económicos» que era preciso paliar. ${ }^{99}$ La aprobación en 1971 del PNHST, ${ }^{100}$ suponía así una muestra del interés del gobierno por continuar desarrollando una serie de actuaciones en las que confiaba como una forma de conseguir su sostenimiento. El Ministro de Trabajo ponía de manifiesto cómo con el PNHST se continuaba pretendiendo alcanzar eso que perseguía desde hacía décadas - la «creación de una conciencia colectiva del problema de los accidentes y las enfermedades profesionales»- a través de una «intensa acción formativa y divulgadora», que ahora se pretendía llevar «a todos los niveles» plasmándola en «acciones visibles desde la escuela primaria a la universidad, desde la empresa a los medios de comunicación social». ${ }^{101}$

\footnotetext{
95 «Decreto 907/1966», 4781-4782.

96 «Orden de 7 de abril de 1970 por la que se encomienda a la Dirección de la Seguridad Social la elaboración de un Plan Nacional de Higiene y Seguridad del Trabajo», BOE 91 (16-abril-1970): 5958-5959.

97 «Decreto 2891/1970, de 12 de septiembre, por el que se crea el Consejo Superior de Higiene y Seguridad del Trabajo», BOE 244 (12-octubre-1970): 16713-16714.

98 «Decreto 2891/1970», 16714.

99 «Orden de 7 de abril», 5959.

100 «Orden de 9 de marzo de 1971 por la que se aprueba el Plan Nacional de Higiene y Seguridad del Trabajo», BOE 60 (11-marzo-1971): 4017-4019.

101 Cfr. «Editorial. Plan Nacional de Higiene y Seguridad del Trabajo». MST 29 (73), (1971): 5-10 (p. 5).
} 
El PNHST establecía que la acción formativa suponía llevar a cabo varias actuaciones. En primer lugar, se trataría de «promover la sensibilización de los diferentes niveles educativos y ambientes donde se va desarrollando la personalidad de los futuros trabajadores». En segundo lugar, habría que «coordinar y normalizar los diferentes cursos formativos que se [dirigieran] a los diversos niveles dentro de las empresas». Por último, debía de operar al objeto de conseguir la formación de especialistas en Higiene y Seguridad del Trabajo a nivel superior y medio. ${ }^{102}$

Una amplia actuación de carácter educativo se dibujaba así al objeto de inculcar en la población trabajadora la importancia de mantener sus cuerpos a salvo de los riesgos laborales. Una serie de entidades —Dirección ejecutiva, Institutos territoriales de Higiene y Seguridad del Trabajo, Consejos Provinciales de Higiene y Seguridad en el Trabajo, Gabinetes Técnicos Provinciales, y Centros de Higiene y Seguridad en el Trabajo- se encargarían de darle apoyo, contribuyendo a configurar un amplio dispositivo destinado a controlar si la labor de persuasión sobre los productores, encaminada a inculcarles las bondades de la acción preventiva frente a los accidentes y enfermedades profesionales, se realizaba adecuadamente.

Para su puesta en marcha, el PNHST iba a contar con un referente importante: la Ordenanza de Higiene y Seguridad en el Trabajo. ${ }^{103}$ Con ella se buscaba intensificar «la puesta en práctica de las oportunas medidas de prevención», así como ordenar las atribuciones y funciones de los órganos de la Administración pública que habrían de proporcionar lo necesario para que fueran eficaces. Recogía también las funciones que debía realizar el Ministerio del Trabajo al objeto de ejercer una «acción tuitiva más eficaz en defensa de la vida, la integridad, salud y bienestar» de las personas que estuvieren comprendidas en el campo de aplicación de la Seguridad Social.

Para lo que nos compete en este artículo, es importante destacar que la Ordenanza continuaba encargando a los Comités de Seguridad e Higiene del Trabajo labores educativas: cuidar de que todos los trabajadores

\footnotetext{
102 «Orden de 9 de marzo de 1971», 4018.

103 «Orden de 9 de marzo por la que se aprueba la Ordenanza General de Seguridad e Higiene en el Trabajo», BOE 64 y 65 (16 y 17-marzo-1971): 4303-4314 y 4383-4396.
} 
recibieran una formación adecuada en materias de Seguridad e Higiene, y «fomentar la colaboración de los mismos en la práctica y observancia de las medidas preventivas de los accidentes del trabajo y enfermedades profesionales»; cooperar en la realización de campañas de seguridad e higiene del trabajo en la empresa, siguiendo las orientaciones del PNHST; y «promover la enseñanza, divulgación y propaganda de Seguridad e Higiene mediante cursillos y conferencias al personal de la Empresa». ${ }^{104}$

La Ordenanza dejaba claro de otra manera el interés del régimen franquista por lograr que los obreros cooperaran en esa tarea formativa que pretendía generar en ellos una sensibilidad hacia la prevención de los riesgos laborales, y lo iba a hacer de un modo más pernicioso para ellos. En efecto, atribuía a los Comités de Seguridad e Higiene del Trabajo la labor de proponer la «imposición de sanciones a quienes incumplan las normas o instrucciones sobre Seguridad e Higiene de obligada observación en la Empresa».105 Hay que tener presente que en el Título Tercero de la Ordenanza, dedicado a las «responsabilidades y sanciones», se establecía que el director de la empresa podía sancionar, «en el ejercicio de su potestad disciplinaria y conforme a procedimiento legalmente establecido", a los trabajadores que infringieran los preceptos de la Ordenanza. ${ }^{106}$ De esta forma, se incorporaba una medida de alto alcance para reducir la resistencia de los productores a colaborar con las medidas encaminadas a luchar contra los riesgos laborales.

La Ordenanza poseía así componentes significativos encaminados a disciplinar a los trabajadores. La tarea destinada a adoctrinarlos para generar esa ansiada «conciencia colectiva» respecto a la necesidad de prevenir los riesgos laborales poseía en esa norma un tono imperativo, que contribuía a destacar el papel de la Medicina del Trabajo entre las disciplinas que permitían el ejercicio de la biopolítica. En concreto, la Ordenanza confería a la educación en Higiene y Seguridad en el Trabajo un fuerte componente medicalizador de las conductas de los obreros,

104 «Orden de 9 de marzo», 4306.

105 «Orden de 9 de marzo», 4306.

106 «Orden de 9 de marzo», 4396. Las sanciones podían ir desde una amonestación verbal, al despido. Sin embargo, no señalaba qué tipo de comportamientos deberían ser castigados de una forma u otra, por lo que se generaba un cierto desamparo para el trabajador. 
que se establecía además de manera coercitiva al indicar que estaban obligados expresamente a: recibir las enseñanzas sobre Higiene y Seguridad que le fueran facilitadas por la empresa o por alguna de las instituciones del PNSHT; usar correctamente los medios de protección personal y cuidar de su perfecto estado y conservación; «cuidar y mantener su higiene personal», en evitación de enfermedades contagiosas; y «someterse a los reconocimientos médicos preceptivos y a las vacunaciones e inmunizaciones ordenadas por las Autoridades sanitarias competentes o por el Servicio Médico de Empresa».107

La Ordenanza ha sido valorada positivamente por los expertos. Se ha señalado que representó una puesta al día útil y eficaz de lo que podía hacerse en esos años en materia de Seguridad e Higiene del Trabajo, y que consiguió dar un gran impulso a la prevención de riesgos laborales. ${ }^{108}$ Cabe decir también que sus contenidos poseían ingredientes destacados de cara a facilitar que, con la ayuda de la enseñanza y la propaganda, se siguiera trasladando a los productores la idea de su responsabilidad en relación con la prevención de los accidentes del trabajo y de las enfermedades profesionales. Además, lo hacía poniéndoles claramente de manifiesto que era su obligación seguir unas determinadas pautas de actuación para evitarlos, y que el fracaso en el cumplimiento de ese cometido podía ser objeto de sanción. La persuasión de los trabajadores, al objeto de estimular su compromiso con el mantenimiento y fortalecimiento de su salud, adquiría así un destacado tono intimidatorio. Aunque la Ordenanza fue derogada en 1995, la norma que la sustituyó, y que permanece vigente, mantuvo esa posibilidad de castigar a quienes se entendiera que no cumplían sus obligaciones en relación con la prevención de los riesgos laborales. ${ }^{109}$

\footnotetext{
107 «Orden de 9 de marzo», 4306.

108 Cfr. Ángel Bartolomé Pineda, «Ordenanza General de Seguridad e Higiene en el Trabajo» en Ángel Bartolomé Pineda y cols., Historia de la Medicina del Trabajo en España (1800-2000) (Madrid: Editorial MAPFRE, 2004), 787-791 (p. 791).

109 La Ordenanza se mantuvo en vigor sin modificaciones hasta 1995, en que fue derogada por: «Ley 31/1995 de 8 de noviembre, de prevención de riesgos laborales», BOE 2699 (10-noviembre-1995): 32590-32611. Esta Ley mantuvo similares obligaciones para los trabajadores que la Ordenanza, y su incumplimiento podía ser también objeto de sanción de acuerdo con su tipificación como «falta» o «incumplimiento laboral».
} 


\section{CAMBIOS ORGANIZATIVOS EN UN PERÍODO DE «TRANSICIÓN»(1976-1980)}

A diferencia de la Ordenanza, el PNSHT tuvo una duración breve. En 1976 fue derogado por un real decreto que atribuía a un nuevo organismo las funciones de ordenación, orientación y desarrollo de acciones en materia de seguridad e higiene del trabajo: el Servicio Social de Higiene y Seguridad del Trabajo (SSHST, en adelante). ${ }^{110}$ Este organismo debía encargase de diferentes actividades relacionadas con la «acción formativa» en materia de higiene y seguridad en el trabajo: formación de especialistas a nivel de titulado medio y superior; la formación de trabajadores desde el nivel básico al de especialización, particularmente a los que fueran a ejercer como vigilantes de seguridad o fueran a formar parte de los Comités de Seguridad e Higiene; la coordinación de las diferentes actividades formativas que se realizaran en empresas; y la «labor de promoción del interés por la seguridad e higiene del trabajo, en los diferentes ambientes, tanto en las empresas, como en los centros privados de enseñanza». Otras acciones que debía desarrollar el SSHST en esa línea educativa eran las de divulgar los conocimientos sobre prevención de accidentes y enfermedades profesionales, y proceder a la preparación de «campañas nacionales, provinciales, locales o sectoriales» al objeto de "fomentar la creación de una conciencia en materia de seguridad e higiene del trabajo».111 De esta manera, tras la muerte de Franco el gobierno continuaba tratando de impulsar la consecución del viejo objetivo de inculcar entre los españoles la necesidad de prevenir los riesgos laborales, y mantenía como herramienta relevante para ello a la enseñanza de la higiene y seguridad del trabajo.

El SSHST tuvo, al igual que el PNSHT, una escasa vigencia. Me refiero únicamente a sus elementos organizativos, porque su modo de percibir el papel de la educación como canalizadora de ese interés por controlar la siniestralidad y las enfermedades laborales iba a tener continuidad en otra entidad: el Instituto Nacional de Higiene y Seguridad en el Trabajo (INHST, en adelante). En efecto, la creación del Ministerio de Sanidad

\footnotetext{
110 «Real Decreto 2133/1976 de 10 de agosto, por el que se modifican los Decretos 9090/1972, de 2 de noviembre, sobre Política de Empleo, y el 535/1975, de 21, de marzo, sobre Reorganización del Ministerio de Trabajo», BOE 223 (16-septiembre-1976): 18089-18093 (pp. 18090 y 18091).

111 «Real Decreto 2133/1976», 18091.
} 
y Seguridad Social en 1977,112 contribuyó, al «unificar competencias dispersas, faltas de planificación y exentas de planificación conjunta», a que se promulgara un Real Decreto-Ley que afectó de manera letal al SSHST. ${ }^{113}$ Según se señalaba en su preámbulo, se pretendía dotar de una mayor eficacia al funcionamiento de los organismos relacionados con la gestión de los problemas de salud, y realizarlo de un modo que permitiera hacerlos, en consonancia con la transformación política hacia la democracia que se estaba produciendo en España, más participativos y transparentes. Como fruto de estos planteamientos, se creó el INHST, al que se le asignaron las funciones y competencias del SSHST.114 Heredaba así la misión de contribuir, mediante sus responsabilidades en relación con la enseñanza de la seguridad e higiene en el trabajo, a la consecución de conseguir unos ciudadanos más concienciados en la necesidad de combatir los riesgos del trabajo. Es más, cuando se reguló en 1982 su estructura y competencias, se estableció explícitamente que, entre las funciones que se le asignaban, se hallaba «divulgar y propagar entre las empresas y la población trabajadora los conocimientos y prácticas de prevención de riesgos profesionales». ${ }^{115}$

Resulta arriesgado establecer hasta qué punto estas actuaciones que he explorado fueron capaces de contribuir a alcanzar ese objetivo que se comportó en ellas como una suerte de leitmotiv: conseguir desarrollar una "conciencia colectiva» sobre la importancia de reducir los accidentes del trabajo y las enfermedades, contribuyendo así a reducir la conflictividad laboral y a aumentar la producción. Aunque determinados comportamientos de los obreros — participación en los cursos, elaboración por ellos de carteles preventivos...- parecen apuntar a que las iniciativas encaminadas a estimular su sensibilidad hacia las consignas que se les transmitían podían estar calando en los trabajadores, algunos testimonios inducen a pensar que la tarea no resultó del todo eficaz.

112 «Real Decreto 1558/1977, de 4 de julio, por el que se reestructuran determinados órganos de la Administración Central del Estado», BOE 59 (5-julio-1977): 15035-15037.

113 «Real Decreto-Ley 36/1978, de 16 de noviembre, sobre gestión institucional de la Seguridad Social, la salud y el empleo», BOE 276 (18-noviembre-1978): 26246-2624 (pp. 62246 y 62248).

114 «Real Decreto-Ley 36/1978», 26247.

115 «Real Decreto 577/1982, de 17 de marzo, por el que se regulan la estructura y competencias del Instituto Nacional de Seguridad e Higiene en el Trabajo», BOE 69 (22-marzo-1982): 7300-7302 (p. 7300). 
En 1978, un técnico de seguridad, al ser interrogado en una entrevista sobre la problemática de la seguridad en su actividad, afirmaba que no habría «más remedio que incidir en el factor humano» $\mathrm{y}$ «mentalizar a los trabajadores en la seguridad». En su opinión, existirían ya bastantes avances técnicos, pero «a veces no se utilizan todo lo que se debiera». Lo único que faltaría es que «la gente empiece de verdad a colaborar, sean conscientes de que es necesario [...] un plan de seguridad».116 También un inspector de Trabajo señalaba, al referirse a la situación en uno de los sectores más castigados por la siniestralidad —el de la construcción-, que «la seguridad no [había] calado». Además, al plantear las medidas a adoptar para mejorar las posibilidades de reducir los riesgos del trabajo, su opinión era que «sería preciso que [...] los trabajadores tomasen una conciencia de la seguridad» y que, después de ello, «tomasen un auténtico protagonismo». ${ }^{117}$ Una opinión similar era mantenida por un trabajador que, ante la pregunta sobre las medidas que recomendaría para bajar la accidentalidad, respondía que sería «fundamental la formación y mentalización de los trabajadores». Desde su punto de vista, si el «personal colabora de verdad y se preocupa honradamente de la seguridad, es decir, de cumplir con todas las normas de prevención, así como de utilizar correctamente los medios de protección personal, no voy a decir que los accidentes bajarían a cero, pero sí que el índice se accidentabilidad sería muy pequeñito». ${ }^{118}$

\section{CONCLUSIONES}

A lo largo del período estudiado, se desarrollaron por tanto en España un significativo número de iniciativas destinadas a promover entre los trabajadores la idea de la necesidad de combatir los riesgos laborales. Consciente de los problemas, humanitarios y económicos que pueden derivarse de los accidentes del trabajo y de las enfermedades profesionales, el régimen franquista contempló a la Medicina del Trabajo como una disciplina que podía ayudarle no solo en relación con esa

\footnotetext{
116 L. Castillo, «Francisco Falcó, Jefe de Seguridad de Edificación. “Todos los accidentes se podrían haber evitado"", Seguridad y Trabajo 6 (1978): 6-7 (p. 7).

117 L. Castillo, «La seguridad no ha calado en grandes sectores de la construcción», Seguridad y Trabajo 11 (1978): 7.

118 L. Castillo, "Carmelo Galvano: Encargado General. "Es fundamental la formación y mentalización de los trabajadores en seguridad”, Seguridad y Trabajo 9 (1978): 6-7 (p. 7).
} 
labor, sino también, con la relativas a crear una menor conflictividad social, un mayor grado de difusión y aceptación de su ideario político y una mayor legitimación.

La Medicina del Trabajo, convertida así en un elemento destacado de la biopolítica del Nuevo Estado, contó con el apoyo de las autoridades para poder consolidarse como una especialidad y contribuir a lo que se planteó como una meta relevante de la política nacional: conseguir la formación de una «conciencia colectiva» sobre la necesidad de prevenir los riesgos laborales.

La acción educativa sobre los trabajadores fue considerada por los expertos como una forma de adecuada para conseguirlo. De este modo, figuró muy tempranamente en las estrategias que los expertos en Medicina del Trabajo propusieron para combatir el problema de los riesgos del trabajo. Su relevancia al respecto creció impulsada por los cambios operados, sobre todo a partir de mediados de siglo, en el modo en el modo de concebir los fines y contenidos de la especialidad. El refuerzo de su vertiente preventiva, y la importante consideración que recibió el llamado "factor humano», impulsaron la enseñanza de la higiene y seguridad en el trabajo entre los trabajadores. Como consecuencia de ello, creció la tendencia a atribuir a los obreros un alto grado de responsabilidad en la aparición de las enfermedades profesionales y los accidentes laborales. La interpretación de estos fenómenos como el resultado de un fracaso del obrero en su obligación de mantenerse sano, condujo a que se hiciera más presente en las normas esa posibilidad, presente ya al alba del Nuevo Estado, y que se mantiene aún en nuestras leyes, de poder sancionar a aquellos productores que se consideraba que vulneraban los mandatos legislativos acerca de la prevención de riesgos laborales.

\section{Nota sobre el autor}

José Martínez-Pérez es Catedrático de Universidad (Historia de la Ciencia) en la Facultad de Medicina de Albacete de la Universidad de Castilla-La Mancha (UCLM), de la que fue decano (2008-2021). Licenciado (1982) y Doctor (1988) en Medicina y Cirugía por la Universidad Complutense de Madrid (UCM), su tarea investigadora se ha dirigido principalmente a estudiar los procesos de intercambio entre medicina y 
sociedad, tomando principalmente como objeto de análisis las relaciones entre la primera y el fenómeno de exclusión social. En 1998 empezó a promover en la UCLM una línea de investigación, entroncada con la anterior, sobre historia de la discapacidad. La actividad la ha desarrollado en el marco de 9 proyectos de investigación, en los que ha actuado como investigador principal. Los resultados han aparecido en revistas como: Asclepio, Dynamis, History of Pschiatry, História, Ciências, Saúde-Manguinhos, Social History of Medicine o Disability Studies Quarterly. Recientemente ha co-editado, junto con el Dr. Enrique Perdiguero-Gil, el libro Genealogías de la reforma sanitaria en España (Madrid: Catarata: 2020).

\section{LISTA DE ABREVIATURAS}

BOE: Boletín Oficial del Estado.

INHST: Instituto Nacional de Higiene y Seguridad en el Trabajo

INMSHT: Instituto Nacional de Medicina, Higiene y Seguridad del Trabajo.

INMST: Instituto Nacional de Medicina y Seguridad del Trabajo.

INP: Instituto Nacional de Previsión.

MST: Medicina y Seguridad del Trabajo. Revista del Instituto Nacional de Medicina y Seguridad del Trabajo.

PNHST: Plan Nacional de Higiene y Seguridad en el Trabajo.

OSME: Organización de los Servicios Médicos de Empresa.

SME: Servicios Médicos de Empresa.

SSHST: Servicio Social de Higiene y Seguridad de la Dirección General del Trabajo.

\section{REFERENCIAS}

Bachiller Baeza, Ángel. La Medicina Social en España (El Instituto de Reeducación y la Clínica del Trabajo 1922-1937). Valladolid: Universidad de Valladolid, 1985.

Barrachina, Marie-Aline. Propagande et culture dans l'Espagne franquiste, 19361945. Grenoble: ELLUG, 1998.

Bartolomé Pineda, Ángel. «Servicios Médicos de Empresa». En Historia de la Medicina del Trabajo en España (1800-2000), editado por Ángel Bartolomé Pineda y cols., 617-637. Madrid: MAPFRE, 2004. 
Bartolomé Pineda, Ángel. «Organización de los Servicios Médicos de Empresa». En Historia de la Medicina del Trabajo en España (1800-2000), editado por Ángel Bartolomé Pineda y cols., 603-616. Madrid: MAPFRE, 2004.

Bartolomé Pineda, Ángel. «Sociedad Española de Medicina del Trabajo». En Historia de la Medicina del Trabajo en España (1800-2000), editado por Ángel Bartolomé Pineda y cols., 639-684. Madrid: MAPFRE, 2004.

Benavides, F. G. «Manuel Baselga, defensor de la salud de los trabajadores», El País, 24 de junio de 2009. https://elpais.com/diario/2009/06/24/necrologicas/1245794401_850215.html

Cayet Thomas, Paul-André Rosental y Marie Thébaud-Sorger. «How International Organisations Compete: Occupational Safety and Health at the ILO, a Diplomacy Expertise». Journal of Modern European History 2 (2009):174195. https://doi.org/10.17104/1611-8944_2009_2_174.

Cayuela Sánchez, Salvador. «La biopolítica en la España franquista». PhD diss., Universidad de Murcia, 2008.

Cayuela Sánchez, Salvador. Por la grandeza de la Patria. La biopolitica en la España de Franco. Madrid: Fondo de Cultura Económica, 2014.

Corbella, Jacint. «Obituario. Un pionero de la medicina del trabajo. Manuel Baselga Monte (1931-2009) Médico», La Vanguardia, 28 de junio de 2009. http:/hemeroteca.lavanguardia.com/preview/2009/06/18/pagina-35/78239 960/pdf.html

Ellwood, Sheelagh. Historia de Falange Española. Barcelona: Crítica, 2001.

Fernández Conradi, Luis y Ángel Bartolomé Pineda. «Instituto Nacional de Medicina y Seguridad en el Trabajo». En Historia de la Medicina del Trabajo en España (1800-2000), editado por Ángel Bartolomé Pineda y cols., 545-570. Madrid: MAPFRE, 2004.

Fernández Gómez, Julio A. «De la Guerra Civil a la Ordenanza General de Seguridad e Higiene del Trabajo (1939-1971)». Sociología del Trabajo 60 (2007): 77-111.

Foucault, Michel. "Il faut defendre la société». Cours au College de France, 1976. Paris: Seuil/Gallimard, 1997.

Foucault, Michel. «Afterword. The Subject and Power». En Michel Foucault: Beyond Structuralism and Hermeneutics, editado por Hubert L. Dreyfuss y Paul Rabinow, 208-226. Chicago: Chicago University Press, 1983.

Foucault, Michel. Histoire de la sexualité 1. La volonté de savoir. Paris: Gallimard, 2003.

Galán García, Agustín y Mónica Ortega Moreno. «La construcción del relato preventivo en España durante el siglo XX». Revista Internacional y Comparada de relaciones laborales y derecho del empleo, 5, n. 3 (2017). http://ejcls. adapt.it/index.php/rlde_adapt/article/view/533/725 
González Sánchez, José Juan. Seguridad e Higiene en el Trabajo. Formación histórica y fundamentos. Madrid: Consejo Económico y Social, 1977.

Martínez-Pérez, José. «La Organización Científica del Trabajo y las estrategias médicas de seguridad laboral en España (1922-1936)». Dynamis 14 (1994): 131-158.

Martínez-Pérez, José. «El obrero recuperado: Medicina del Trabajo, Ortopedia y el impacto de la tecnología médica sobre la imagen social de las personas con discapacidades (España, 1922-1936)». História, Ciencias, Saúde - Manguinhos 13 (2006): 349-373.

Martínez-Pérez, José. «Work, Disability and Social Control: Occupational medicine and Political Intervention in Franco's Spain (1938-1965)». Disability Studies Quarterly 37, n. ${ }^{4}$ (2017). http://dx.doi.org/10.18061/dsq.v37i4.6098

Martínez-Pérez, José. «Reforma sanitaria e introducción de una nueva cultura de la salud en España: acerca del discurso sobre Medicina, Higiene y Seguridad en el trabajo (1940-1982)». En Genealogías de la reforma sanitaria en España, editado por José Martínez-Pérez y Enrique Perdiguero-Gil, 215239. Madrid; Catarata, 2020.

Martínez-Pérez, José y Mercedes Del Cura, «Work injuries, scientific management and the production of disabled bodies in Spain, 1920-1936». En The Imperfect Historian - Disabilities Histories in Europe, editado por Sebastian Barsch, Anne Klein y Pieter Verstraete, 191-213. Frankfurt am Main: Peter Lang, 2013.

Martínez-Pérez, José y Mercedes Del Cura. «Bolstering the greatness of the Homeland: Productivity, Disability and Medicine in Franco's Spain (19401966)». Social History of Medicine 28, n. 4 (2015): 805-824. https://doi.org/ 10.1093/shm/hkv060

Martínez-Pérez, José y Mercedes Del Cura. «Divulgando nuevas ideas sobre la diversidad humana: la dimensión educativa del discurso sobre la discapacidad en la España franquista», Asclepio 71, n. ${ }^{\circ} 1$ (2019). https://doi.org/10.39 89/asclepio.2019.07

Mascías, Eduardo. «Escuela Nacional de Medicina del Trabajo». En Historia de la Medicina del Trabajo en España (1800-2000), editado por Ángel Bartolomé Pineda y cols., 759-769. Madrid: MAPFRE, 2004.

Menéndez Navarro, Alfredo. «Médicos, medicina y salud laboral en España. Una mirada constructivista al abordaje de las enfermedades profesionales, 1900-1975». La Mutua 18 (2007): 171-189.

Menéndez Navarro, Alfredo y Esteban Rodríguez-Ocaña. «From “Accident Medicine" to "Factory Medicine": Spanish Occupational Medicine in the Twentieh Century». En Origins of Occupations Health Associations in the World, editado por A. Grieco et al., 207-216. Amsterdam: Elsevier, 2003. 
Melling, Joseph y Christopher. Sellers. «Objetive Collectives? Transnationalism and "Invisibles Colleges" in Occupational and Environmental Health from Collis to Selikoff». En Dangerous Trade. Histories of Industrial Hazards across a Globalizing World, editado por Christopher Sellers y Joseph Melling, 113-125. Philadelphia: Temple University Press, 2012.

Molinero, Carme. La captación de las masas. Política social y propaganda en el régimen franquista. Madrid: Cátedra, 2005.

Montoya Melgar, Alfredo. Ideología y las Leyes Laborales de España (1873-1978). Madrid: Civitas, 1992.

Palomeque López, Manuel Carlo. «La Ordenación Jurídica de la seguridad e higiene en el trabajo durante el primer y segundo franquismo, de la Guerra Civil a la Ordenanza General, 1939-1971». En Historia de la prevención de riesgos laborales en España, 122-139. Madrid: Fundación Francisco Largo Caballero-Fundación $1^{\circ}$ de Mayo-Instituto Nacional de Seguridad e Higiene en el Trabajo, 2007.

Perdiguero-Gil, Enrique. "La “educación sanitaria” en el ideario médico-social del franquismo a través de la revista SER». En Política, salud y enfermedad en España: entre el desarrollismo y la transición democrática, editado por Enrique Perdiguero-Gil, 117-135. Alicante: Universidad Miguel Hernández de Elche, 2015. https://editorial.edu.umh.es/2015/12/09/politica-salud-y-enfermedad-en-espana-entre-el-desarrollismo-y-la-transicion-democratica/

Pons-Pons, Jerònia y Margarita Vilar-Rodríguez. La gestión del Seguro de Accidentes en España: de Mutuas Patronales a entidades colaboradoras de la Seguridad Social, 1900-2019. S.1.: Ministerio de Inclusión, Seguridad Social y Migraciones - Editorial MIC, 2020.

Rodríguez Carmona, Manuel. «Prólogo». En Historia de la Medicina del Trabajo en España (1800-2000), editado por Ángel Bartolomé Pineda y cols., XXIII-XXXII. Madrid: MAPFRE, 2004. 